\title{
Self-Gravity, Self-Consistency, and Self-Organization in Geodynamics and Geochemistry
}

\author{
Don L. Anderson \\ Seismological Laboratory, Caltech, Pasadena, California \\ "... it is a privilege to see so much confusion." \\ -Marianne Moore, The Steeple-Jack
}

\begin{abstract}
The results of seismology and geochemistry for mantle structure are widely believed to be discordant, the former favoring whole-mantle convection and the latter favoring layered convection with a boundary near $650 \mathrm{~km}$. However, a different view arises from recognizing effects usually ignored in the construction of these models, including physical plausibility and dimensionality. Self-compression and expansion affect material properties that are important in all aspects of mantle geochemistry and dynamics, including the interpretation of tomographic images. Pressure compresses a solid and changes physical properties that depend on volume and does so in a highly nonlinear way. Intrinsic, anelastic, compositional, and crystal structure effects control seismic velocities; temperature is not the only parameter, even though tomographic images are often treated as temperature maps. Shear velocity is not a good proxy for density, temperature, and composition or for other elastic constants. Scaling concepts are important in mantle dynamics, equations of state, and wherever it is necessary to extend laboratory experiments to the parameter range of the Earth's mantle. Simple volume-scaling relations that permit extrapolation of laboratory experiments, in a thermodynamically self-consistent way, to deep mantle conditions include the quasiharmonic approximation but not the Boussinesq formalisms. Whereas slabs, plates, and the upper thermal boundary layer of the mantle have characteristic thicknesses of hundreds of kilometers and lifetimes on the order of 100 million years, volume-scaling predicts values an order of magnitude higher for deep-mantle thermal boundary layers. This implies that deep-mantle features are sluggish and ancient. Irreversible chemical stratification is consistent with these results; plausible temperature variations in the deep mantle cause density variations that are smaller than the probable density contrasts across chemical interfaces created by accretional differentiation and magmatic processes. Deep-mantle features may be convectively isolated from upper-mantle processes. Plate tectonics and surface geochemical cycles appear to be entirely restricted to the upper $\sim 1,000 \mathrm{~km}$. The $650-\mathrm{km}$ discontinuity is mainly an isochemical phase change but major-element chemical boundaries may occur at other depths. Recycling laminates the upper mantle and also makes it statistically heterogeneous, in agreement with high-frequency scattering studies. In contrast to standard geochemical models and recent modifications, the deeper layers need not be accessible to surface volcanoes. There is no conflict between geophysical and geochemical data, but a physical basis for standard geochemical and geodynamic mantle models, including the two-layer and whole-mantle versions, and qualitative tomographic interpretations has been lacking.
\end{abstract}

Earth's Deep Mantle: Structure, Composition, and Evolution

Geophysical Monograph Series 160

Copyright 2005 by the American Geophysical Union

$10.1029 / 160 \mathrm{GM} 11$ 


\section{INTRODUCTION}

The "classical" models of mantle structure and evolution are the whole-mantle convection, or pyrolite, model [Ringwood, 1975] with deep slab penetration, and the tworeservoir model [e.g., DePaolo and Wasserburg, 1976; Allegre, 1982] with an undegassed primitive lower mantle. The recognition of fundamental problems with these models gave rise to an alternative chemically stratified mantle model with essentially all of the incompatible and heat-producing elements residing in the crust and inhomogeneous upper mantle [Anderson, 1983, 1989a]. In this model, most of the mantle, by mass balance, is infertile and large-ionlithophile (LIL)-depleted and the deep mantle is inaccessible because of its high intrinsic density. This model (the Theory of the Earth [TOE] model), essentially the inverse of the above models, is justified and described elsewhere [Anderson, 1989a, 2002a] and will not be part of the present conversation until the other models-the classical and the so-called standard models-are dealt with. The recent widespread recognition - or re-recognition [e.g., Zindler and Hart, 1986] - of problems with the two-reservoir model has led a proliferation of modifications and a return to variants of the whole-mantle convection scheme of Ringwood [1975]. These new hybrid models are designed to explain one or two features but often conflict with other observations. It is not always clear that these complex conceptual models are any more physically realistic than the classical models [e.g., van Keken et al., 2002]. There is now a feeling of crisis and frustration amongst specialists in mantle geochemistry. Francis Albarède, in his Plenary Lecture of the European Union of Geosciences meeting in 2001, put it well (www.theconference.com/JConfAbs/6/Albarede.html):

The paradigm of layered mantle convection was established nearly 20 years ago, mostly based on geochemical mass balance and heat budget arguments. It is now stumbling over the difficulty imposed by convection models to maintain a sharp interface in the mantle at mid-depth and by overwhelming tomographic evidence that at least some of the subducting lithospheric plates are currently reaching the core-mantle boundary. Discontinuities in the deep mantle...remain elusive...The present situation...remains frustrating because the reasons why the layered convection model was defended in the first place are still there and do not find a proper answer with the model of homogeneous mantle convection ...the imbalance between heat flow and heat production requires that the deep mantle is rich in $\mathrm{U}, \mathrm{Th}$, and $\mathrm{K}$... the imbalance of some refractory lithophile elements between the composition of the Earth estimated with a homogeneous mantle and the composition of chondrites leaves a number of 'paradoxes' unresolved...convective mixing should take place with a characteristic time of less than $1 \mathrm{~Gy}$ and should essentially wipe out mantle isotopic heterogeneities. In addition, frustrating evidence that the lower mantle hides a geochemical 'black box', with a non-primitive composition and hardly accessible to observation, is mounting.

Albarède and Boyet [2003] hint at the power of a false color image in upsetting a paradigm that 20 years of paradoxes and more quantitative developments in geophysics had not:

For more than a decade, conflicting evidence between seismic tomography and isotope geochemistry of rare gases has thwarted the construction of a unifying convection model and blurred our vision of lower mantle chemistry and mineralogy. All body wave models vividly depict lithospheric plates penetrating the $660 \mathrm{~km}$ discontinuity...

\section{PRELUDE-ASSERTIONS \& SEMANTICS}

What is the conflicting evidence? Are the paradoxes real, or are they the result of nonphysical assumptions or data selection? The purpose of this paper is to review the evolution of ideas in mantle geochemistry and dynamics, to test these ideas for physical plausibility, and to address the concerns raised above and, repeatedly, elsewhere [e.g., Albarède and van der Hilst, 1999, 2002a,b; hereafter referred to as $A v d H]$. The models mentioned above are motivated almost entirely by one-dimensional (1D) box-model constructs, body-wave travel-times, vivid 2D color images, and purely thermal interpretations of these images and of melting anomalies in the mantle. Many unstated assumptions behind the assertions will be brought up front, reassessed, and dropped. The idea that the mantle is subdivided into a small number of large, isotopically distinct, homogeneous, and accessible reservoirs, separated by major seismic discontinuities, has dominated recent thinking in mantle geochemistry and geodynamics, but it has never had a sound theoretical underpinning, nor was it a unique interpretation of the data [e.g., Zindler and Hart, 1986]. Furthermore, it conflicted-and still conflicts--with a wide variety of evidence in many disciplines, including isotope geochemistry itself.

The paradigm that has been called the standard model of mantle geochemistry [e.g., Hofmann, 1997] is a twobox model with a semi-isolated leaky lower layer and a well-stirred and homogenized upper layer-above $650-\mathrm{km}$ depth. The original standard model attributed nonridge basalts-so-called melting anomalies - to mixtures between depleted and primitive mantle, with no enriched components. 
The two-layer model has generated a number of paradoxes and problems, including the current "crisis", and is responsible for a proliferation of increasingly complex, contrived, and contradictory models for mantle structure, evolution, and convection. The idea of a homogeneous, depleted (i.e., stripped of LIL or crustal elements), well-stirred, upper mantle ('the convecting mantle') and an undepleted ("primitive", with chondritic abundances of all elements, including the noble gases) gas-rich lower mantle (PM), starting at the major mantle phase boundary, is a direct consequence of assumptions, not of data or calculation. The model itself has elements of the Maxwell Demon paradox.

The isotope-based box-models replaced the petrologybased homogeneous pyrolite (deep slab penetration) model of Ringwood [1966, 1975], although both involve an unprocessed primitive mantle. These models assume major element homogeneity, or do not address bulk chemistry at all, or assume relationships between major elements (tomography) and isotopes.

\subsection{Reservoirs vs. Components}

Magmas from mid-ocean ridges (MORB) and ocean islands (OIB) are chemically distinct and are traditionally attributed to separate, isolated reservoirs, e.g., the two-layer model. It is assumed that the MORB source is the "depleted upper mantle" (DUM), the residue after removal of the continental crust (CC) from PM; CC, DUM, and PM are the only three reservoirs. This was first modeled by Jacobsen and Wasserburg [1979], using calculations commonly termed "box models". Other magmas were treated as simple mixtures between melts from DUM and PM (lower mantle). Some OIB were considered as pure PM from the deep mantle [O'Nions et al., 1980]; the upper mantle, by definition, had no enriched material. Terrestrial heat flow and estimates of the abundances of $U$ and $T h$ cannot be explained by a mantle composed entirely of MORB and residual peridotites; the remaining heat sources are usually hidden at great depths in isolated reservoirs, either in the unprocessed PM or in a thin radioactive layer.

Refined mass-balance calculations, which include major elements, are consistent with a mantle that is almost entirely depleted in LIL (80-90\% infertile peridotite and pyroxenite, and about $7 \%$ basalt such as MORB; see Chapter 8 in Anderson, 1989a). The estimated K content of the Earth is $151 \mathrm{ppm}$ and the ${ }^{40} \mathrm{Ar}$ in the atmosphere represents $77 \%$ of that produced over $4.5 \mathrm{Ga}$; this observation alone rules out the standard model. A very small fraction of enriched material (EM), such as CC, enriched-MORB (EMORB), $\mathrm{OIB}$, and kimberlite is all that is needed to give chondritic abundances of the refractory trace elements, including $U$ and $\mathrm{Th}$. For example, kimberlitic magma need amount to only $0.085 \%$ of the mantle to account for the missing heatproducing elements. This amount of EM-which is complementary to depleted material (DM) and CC-could be stored beneath continents, below oceanic plates, in the perisphere, or elsewhere in the upper mantle or transition zone (TZ). A layer of kimberlite only $2 \mathrm{~km}$ thick suffices, or a layer 20 $\mathrm{km}$ thick with $10 \%$ of the LIL concentrations of kimberlite. Such amounts of enriched material in the shallow mantle cannot be ruled out; if they exist, there is no need for a vast unprocessed primitive reservoir or deep U-rich layers. Enriched magmas such as EMORB and OIB erupt in the ocean basin, and continental flood basalts are associated with continental break-up or rifts. It is only by assumption that these are excluded from upper mantle inventories and attributed to a leaky deeper reservoir. Additionally, a large fraction of the surface heat flow is due to secular cooling, not radioactive decay.

Reservoir-or layered-models are not the only way to satisfy geochemical constraints [Zindler and Hart, 1986]. Meibom and Anderson [2003] propose an alternative hypothesis: Rather than being divided into isolated reservoirs, the mantle is fertilized, filtered, and sampled by various platetectonic processes; large-scale averaging at ridges explains why extreme compositions are apparently missing there. Removal of small-degree melts and other EM at subduction zones and elsewhere creates DM and complementary shallow enriched or metasomatized regions.

\subsection{Conflicts and Paradoxes}

There are a large number of geochemical paradoxes (sometimes called enigmas, dilemmas, conundrums, or surprises) associated with what is nominally a model based on geochemistry-a sure sign that the model is wrong. The notion developed among some workers that there is a conflict between geophysics and geochemistry [e.g., Silver et al., 1988; van der Hilst et al., 1997] rather than simply strong evidence against the standard 1D box model of geochemistry [e.g., Zindler and Hart, 1986]. The view of conflict and paradox is widespread [e.g., Becker et al., 1999; Coltice and Ricard, 1999; Helffrich and Wood, 2001; Ballentine et al., 2002] although it basically goes back to a single thermal interpretation of a 2D seismic image on the one hand, and a nonunique box model on the other. All of these authors make modifications to the standard models in order to satisfy a given observation. Few authors itemize or evaluate the "conflicting" geophysical or geochemical evidence (see Appendix 1) but refer only to models that are mainly a result of assumptions, unphysical scaling relations and ad hoc interpretations. The assumptions underlying the standard models have remained intact. 
Allegre [1997] stated that it is increasingly accepted that the Earth's mantle has a two-layer structure. Kamber and Collerson [1999] also claimed that "growing geophysical and geochemical evidence" supported the original "standard" two-layer model. At the same time, van der Hilst et al. [1997 and elsewhere] stated their view, which they call a consensus, that slabs of subducted lithosphere sink deep into the "lower mantle", contradicting the two-layer model, and that present-day mantle convection is "therefore" predominated by whole-mantle flow. This was also a contested view in 1979 [e.g., Anderson, 1979; Elsasser et al., 1979]. Ringwood [1975] thought that eclogite was denser than pyrolite, at all depths, and argued for deep slab penetration and a chemically homogeneous mantle, whereas Anderson [1979, 1989b] argued that eclogite would be trapped in the transition zone (see Figure 1). What is meant by deep penetration is often confusing because the classical lower-mantle boundary is at 1,000-km depth [Birch, 1952], not at $650 \mathrm{~km}$. These models will be referred to separately as the two-layer, or standard, model and the whole-mantle model, and together as the standard—or classical—models. Becker et al. [1999] argue that "neither end-member scenario is tenable". Both of these models are "whole-mantle" in the sense that material from all depths in the mantle is assumed to be accessible to surface volcanoes. Also in 1997 Hofmann [1997] recognized the problems and summarized attempts to modify and fix the standard models, mainly by changing the geometry of the reservoirs. However, certain key assumptions were retained; that is, primordial undegassed or less-degassed regions survive in the deep mantle, "high" ${ }^{3} \mathrm{He} /{ }^{4} \mathrm{He}$ ratios imply high ${ }^{3} \mathrm{He}$ contents and an undegassed reservoir, enriched components do not exist in "the convecting mantle" (e.g., the MORB reservoir), all regions of the mantle are accessible, temperature is the main variable in controlling physical properties and melting anomalies, and solid-state convective stirring-rather than recycling, magma blending, and sampling theory-is responsible for magma heterogeneity or homogeneity and the scales of heterogeneity. The standard models thus have basically been replaced by a standard set of inviolate assumptions. Various paradoxes can be traced directly to these assumptions-geometric details are less important-and to things that are ignored, such as physics (e.g., effects of pressure, thermodynamic consistency) and statistics (e.g., sampling theory and the central limit theorem).

Some very recent modifications to the standard models [e.g., van Thienen et al., this volume] retain the ideas that oceanic ridges tap the shallowest mantle; ocean island volcanoes tap deep primitive reservoirs; there must be deep, radioactive-rich layers; and oceanic crust-including thickcrust plateaus - must sink deeply into the lower mantle.
Since, in all these models, critical processes occur deep in the mantle, the effects of pressure are of prime importance but are almost always ignored. The standard models are built on geochemistry and seismic body-wave travel times and do not address physical plausibility or the effects of pressure or scale. Other geophysical techniques and physical considerations have been brought to bear on the problem, with quite different results.

\subsection{Seismological Layers}

The classical 1D seismological models of the mantle included a TZ between 400 - and $1,000-\mathrm{km}$ depth that was attributed to phase changes in mantle minerals [Birch, 1952]. The Repetti discontinuity near $1,000-\mathrm{km}$ depth was the single abrupt feature between Moho and the core-mantle boundary. By 1970 seismologists had identified about six seismic discontinuities in the mantle: a major one near 630$\mathrm{km}$ depth and others at $280,520,940,410$, and $1,250 \mathrm{~km}$ [e.g., Whitcomb and Anderson, 1970; for updates on mantle discontinuities see Bina, 1991; Revenaugh and Jordan, 1991; Deuss and Woodhouse, 2002]. Although the attention of geochemists and geodynamicists has been focused on the better known 410 - and $650-\mathrm{km}$ features, about 10 discontinuities in the mantle have been identified by a variety of highresolution or correlation techniques and are, roughly, in the depth intervals of $60-90,130-170,220,280-320,400-415$, $500-560,630-670,800-940,1,250-1,320$, and 2,500-2,700 $\mathrm{km}$. Negative velocity jumps have been reported from depths of 380, 410,450,610, and $720 \mathrm{~km}$ [Fee and Dueker, 2004; Song et al., 2004]. Some of these discontinuities are probably chemical in nature and some are apparently highly variable in depth (the reports of reflections or scatterers between $800-$ and $1,320-\mathrm{km}$ depth may all be due to a few highly irregular interfaces). There are numerous reflectors and scatterers in the shallow mantle above about $220-\mathrm{km}$ depth [e.g., Deuss and Woodhouse, 2002; Levander and Niu, 2003; Rost and Garnero, 2004]. Thus, the mantle is not as simple as it appears from global tomography or as implied by the standard models.

Interpretation of the $410-$ and $\sim 630-\mathrm{km}$ discontinuities as phase changes had been firmly established by 1970 . Thermochemical calculations showed that the depths and the abrupt increases in seismic velocity could be explained by phase changes in olivine [Akimoto, 1969; Anderson, 1967a, 1970]. The phase change interpretation received strong support from static high-pressure experiments on analog compounds in Australia and shock wave experiments on silicates in the United States (see Ahrens et al., 1969; Ringwood, 1975). The predicted postspinel breakdown to rock salt and perovskite structures was achieved in several labs in 


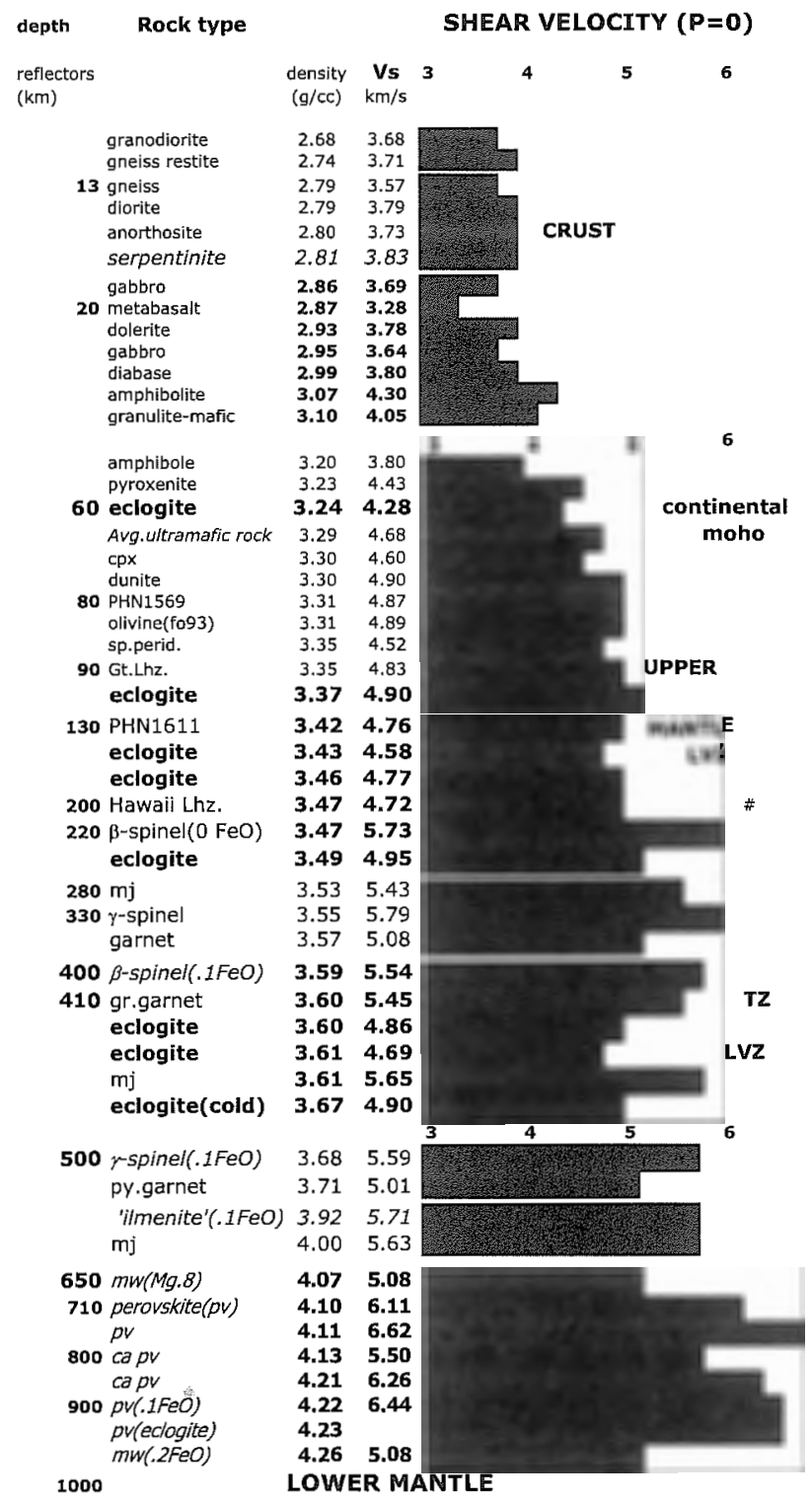

Figure 1. Density and shear velocity of crustal and mantle minerals and rocks, at standard $T$ and $P$, tabulated and arranged according to increasing density. This approximates the situation in an ideally chemically stratified mantle. $P$ and $T$ effects may change the ordering and the velocity and density jumps. Eclogite can settle to various levels, depending on composition; the deeper eclogite bodies have lower velocity than other rocks of similar density. Eclogite has a much lower melting point than peridotites and will eventually heat up and rise, even if it is not in a TBL. The ilmenite form of garnet and enstatite is stable at low temperature but will convert to more buoyant phases as it warms. Velocity decreases do not necessarily imply hot mantle. Song et al. [2004] and Fee and Dueker [2004] found LVZs at various depths above $720 \mathrm{~km}$. Also shown are the approximate depths of prominent or robust reflections from the mantle; they are not necessarily due to the adjacent lithologies.
1976-1978, confirming the thermochemical calculations and inferences from shock waves and analog compounds. The predicted negative Clapyron slope was confirmed by calorimetric measurements. The phase change hypothesis for both the $410-\mathrm{km}$ and the $650-\mathrm{km}$ discontinuities was generally accepted by 1970 , and there were numerous candidates for the other discontinuities. The alternate view-that major chemical changes were responsible for the major seismic discontinuities - came later; it was not the initial explanation. The numerous minor reflectors, however, may be due to chemical interfaces (Figure 1). Subducting slabs may be trapped at various depths, including phase changes, and may be responsible for complicating reflections from the phase change boundaries.

\subsection{Isotopic Reservoirs}

Between 1979 and 1987, isotope geochemists developed a two-reservoir model, with continuous continental growth and, initially, no recycling. They assumed that the still growing $\mathrm{CC}$ was being extracted from some fraction of PM, leaving behind a depleted (upper) and an undifferentiated (deeper) reservoir. They did not challenge the phase change hypothesis; they seemed unaware of it.

Some early mass-balance calculations suggested that about $30 \%$ of the mantle could be depleted, assuming $100 \%$ efficiency, to form the $\mathrm{CC}$, and that this corresponded to the volume of the upper mantle. Estimates of errors [Allegre et al., 1983; Anderson, 1983; Zindler and Hart, 1986] cast doubt on this. Some other early calculations suggested perhaps $50 \%$ of the mantle was depleted [DePaolo, 1980; O'Nions et al., 1980]. Refined calculations permitted much more extensive processing of the mantle, up to $90 \%$ [e.g., Zindler and Hart, $1986]$. It is now clear that at least half, and perhaps $80 \%$, of the original LIL budget of the mantle resides in the CC, lithosphere, upper mantle, and (in the case of argon) atmosphere, thereby reversing the original conclusions that motivated the standard model. Some mass-balance calculations-including the ${ }^{40} \mathrm{Ar}$ in the atmosphere-required $>70 \%$ of the mantle to be depleted [Anderson, 1983; Zindler and Hart, 1986], which, following the box-model logic, should be equated with the lower mantle. Mass-balance calculations are consistent with a LIL-depleted and infertile lower mantle that is complementary to the crust and to the olivine-rich shallow mantle [Anderson, 1983].

Numerous other geochemical components were identified, and the box model concept soon required five or six isolated reservoirs or layers instead of two, plus recycling. These components have similarities to surficial reservoirs (sediments, crust, delaminated lower crust, lithosphere, seawater, air) but they were also placed in the deepest mantle, by 
assumption. The isotopic evidence for various components in the mantle did not imply a layered mantle or deep sources, but "the depleted reservoir" was invariably associated with the upper mantle and the others were placed in the lower mantle. DM - and the other "reservoirs"-could have been placed anywhere in the mantle, or distributed; isotopes and mass-balance cannot constrain this [Zindler and Hart, 1986]. The bottom line: Geochemical data do not constrain the depths or configurations of reservoirs, and the early isotope papers did not claim that they were; no reference was made to seismological discontinuities. Geochemical data are not responsible for the perceived crisis.

\subsection{Geodynamic Constraints}

Early geodynamic modelers assumed that mantle convection was mainly restricted to the low-viscosity upper mantle or asthenosphere. Elsasser et al. [1979], however, argued that if the plates are the upper boundary layer of mantle convection, then the depth of the system should be comparable to the sizes of plates, or thousands of kilometers. There have been very few simulations of layered convection and none with realistic geometries or physical properties. Nevertheless, the few that exist are instructive. Two-layer simulations of convection and shallow return-flow models are able to satisfy geophysical observations [McKenzie and Richter, 1981; Cizkova and Matyska, 2004] including heat flow and apparent slab penetration into the deeper layer. A layered model with a major element chemical interface near $900 \mathrm{~km}$ at the base of Bullen's TZ explains both the geoid and the dynamic topography [Wen and Anderson, 1997], which a boundary at $650 \mathrm{~km}$ does not. Chemically heterogeneous or chemically stratified models in general cannot be ruled out. What models can be ruled out, however, are the original mass-balance and primitive undegassed lower mantle models; models that ignore recycling [e.g., DePaolo and Wasserburg, 1976; Jacobsen and Wasserburg, 1979]; radioactivity-rich lower mantle models; whole-mantle convection schemes based on qualitative tomographic interpretations [e.g., van der Hilst et al., 1997]; geoid models that do not satisfy long-wavelength topography; layered models that consider the $650-\mathrm{km}$ phase boundary to be primarily a chemical or isotope boundary or the only plausible barrier to convection; thermal models that ignore secular cooling; and layered models with shear-coupling across layers. None of this implies a conflict between geochemistry and geophysics. Mantle convection and stirring schemes based on heating from below, 2D geometry (Cartesian or axi-symmetric boxes), and the Boussinesq approximation (ignoring pressure effects on physical properties) should not be viewed as definitive [Bunge et al., 2001; Tackley, 1998]; nonetheless, they have been quoted as contributing to the crisis. There is still a large universe of models, including more physically plausible ones, that cannot be ruled out.

Different scenerios, consistent with high-temperature accretion, a heterogeneous mantle, and gravitational stratification, have been proposed using petrological, major element, and classical physics considerations [e.g., Birch, 1952; Agee, 1990; Agee and Walker, 1988; Anderson, 1987b, 1989a,b; Gasparik, 1997; Mattern et al., 2005] and based on quantitative analyses of tomography [e.g., Scrivner and Anderson, 1992; Wen and Anderson, 1995; Gu et al., 2001; Anderson, 2002a; Ishii and Tromp, 2004; Trampert et al., 2004], sampling theory [Meibom and Anderson, 2003], and dynamic topography and plate reconstructions [Wen and Anderson, 1997]. Geophysical and thermodynamic data taken as a whole are consistent with a chemically and convectively inhomogeneous mantle that is quite different from the standard models currently being modified and debated.

The evidence for a major phase-change boundary at 650 $\mathrm{km}$ depth is not new but apparently it helped precipitate the crisis. As recently as 2002, van Keken et al. [2002] state that "the strong seismic reflector at $670-\mathrm{km}$ depth has generally been assumed to be a flow barrier...a major chemical discontinuity" and according to Helffrich and Wood [2001], "The seismic discontinuities at 410 and $660 \mathrm{~km}$ depth initially appeared to be likely boundaries for the compositional layering". This is not correct.

The early isotope mass balance and two-layered convection papers made no reference to seismic discontinuities. The initial discovery of these discontinuities by seismologists 10 years earlier was immediately followed by thermodynamic calculations that showed that their depths and other characteristics - such as sharpness - were generally consistent with isochemical phase changes, the $410-\mathrm{km}$ one being primarily due to the olivine--spinel phase change and the $650-\mathrm{km}$ one due to a spinel-postspinel phase change with a negative Clapyron slope [Anderson, 1967b]. (The 650-km mantle discontinuity is widely referred to as the " 660 " or " 670 " $\mathrm{km}$ discontinuity, but the observed range in depths is at least 30 $\mathrm{km}$ and the global average depth is $650 \mathrm{~km}$.) Previously, the 400-1,000 km depth interval was attributed to a spread-out phase change [e.g., Bullen, 1947; Birch, 1952; Ringwood, 1966]. The phase change interpretation of the upper mantle seismic discontinuities [Akimoto, 1969; Anderson, 1970] has been firmly established for some time and neither was involved in early geodynamic and geochemical models. Neither mass balance nor seismology requires a chemical change at $650 \mathrm{~km}$, and convection simulations do not imply whole-mantle convection or rapid mixing. Geodynamic data do not conflict with geochemical and geophysical data, although some convection models do. 


\subsection{Mantle Filters}

Tomographic studies suggesting that some slabs cross 650 $\mathrm{km}$ depth do not imply that all do, or that key trace elements and isotopes avoid subduction zone processes and are recycled into the deep mantle. The TZ may act as a petrological filter [e.g., Zindler and Hart, 1986]. Recycled material can also be trapped at other depths, both deeper and shallower; thick, cold slabs can sink further and take longer to warm up; younger slabs or those with thick crust tend to underplate continents. Slabs dehydrate and sediments get stripped off at shallow depths. Small-degree melts and LIL are also removed from the mantle in high thermal-gradient regions of the lithosphere, and on the wings of ocean ridge melting domains.

Subduction zone processing is the most severe filter; sediment melting, eclogitization, and slab erosion remove LIL from the slab. Dehydration and partial melting filter out LIL. The dry and depleted residual phases - peridotites and eclogites-equilibrate at various depths, and the removed material metasomatizes the shallow mantle (the mantle wedge, the perisphere, and the plate). Young oceanic plates, subducted seamount chains, ridges, and plateaus thermally equilibrate and melt at depths different from those for older, thicker plates.

The $650-\mathrm{km}$ discontinuity, with its negative Clapyron slope, is a temporary barrier to cold sinking material of the same composition; if the conditions are right, however, such material can eventually break through. A different material, with higher-pressure phase changes, e.g., eclogite, can be stranded by phase changes in peridotite. Eclogite can density-equilibrate at depths above $600 \mathrm{~km}$ (Figure 1). Chemical discontinuities, even those with very small density jumps, can be a barrier-or filter - to through-going convection. The high-viscosity mesosphere may also play a role in stratifying the mantle [Cizkova and Matyska, 2004].

Fertile depleted material-e.g., non-MORB source-is not necessarily the shallowest mantle; it appears in purest form at mature and fast-spreading ridges, not at the onset of continental breakup, or the initiation of spreading, or even on the flanks of spreading centers. Metasomatic fluids and magmas infiltrate the shallow mantle and are more likely to be sampled at the onset - or termination - of spreading than at mature ridges. Delaminated continental crust is a particularly potent source of mantle heterogeneity and melting anomalies; it starts out warmer and equilibrates faster than subducted oceanic crust. Large, fertile, low-melting point blobs can be responsible for "melting anomalies". These recycling, filtering, and sampling processes can explain many geochemical observations while avoiding the pitfalls associated with isolated mantle reservoirs and deep penetration of all slabs and all components.

\subsection{Why a Crisis Now?}

Fundamental problems with the standard model - and the assumptions underlying it - had been identified early on [e.g., Armstrong, 1981; Allegre, 1982; Anderson, 1982a, 1982b; Zindler et al., 1984] and it has been essentially abandoned by isotope geochemists for some time [Hofmann, 1997]. Armstrong [1991] reviewed the early history of the standard model, which he called a "myth". Completely different chemically layered models were developed that overcame the problems with the two-layer and Ringwood-Elsasser models [e.g., Anderson, 1979, 1989a; Agee, 1990]. A large number of models are presumably consistent with both the geophysical and the geochemical data, even if the standard models are not [Zindler and Hart, 1986]. Seismic data have very little to say about isotopes, and isotopes cannot constrain mantle stratigraphy.

Why then do we suddenly have a conflict or a crisis? What happened? In addition to the rediscovery of the 650$\mathrm{km}$ phase boundary and the nonuniqueness of mass-balance calculations, isotope geochemists--who previously supported the standard model [e.g., Ballentine et al., 2002] -most commonly refer to a paper by van der Hilst et al. [1997] and a widely reproduced dramatic color cross-section from this milestone paper. Visual, or intuitive, interpretations of these images, qualitative chromotomography (QCT), and the association of color with temperature has had enormous cross-disciplinary impact, more so than quantitative and statistical analysis of tomographic inversions. The visual impression of a tomographic image, the assumed implications regarding isotopic as well as major element recycling, and the plausibility or implausibility of layering and survival of heterogeneities in a convecting mantle are now at the heart of the perceived crisis. These are issues related to mineral properties, physics, and scaling to large systems but not to isotope geochemistry or even seismology.

\subsection{Overwhelming Tomographic Evidence?}

The view expressed by van der Hilst, Albarède, and others, although widely held in the isotope geochemistry community, is not a consensus view of seismologists, primarily because body-wave tomography is a powerful but imperfect tool. Travel-time tomography, used alone, is particularly limited. The results depend crucially on the ray geometry, which is constrained by the geometry of earthquakes and seismic stations [Vasco et al., 1994] and, to a lesser extent, by the details of the mathematical techniques employed [Spakman and Nolet, 1988; Spakman et al., 1989; Shapiro and Ritzwoller, 2004]. Seismic ray coverage is sparse and spotty. Moreover, the visual appearance of displayed results depends on the 
color scheme, reference model, cropping, and cross-sections chosen. The resulting images contain artifacts that appear convincing [Spakman et al., 1989]. Even further difficulties result from the limitations of present algorithms, which cannot correct completely for finite frequency, source, and anisotropic effects and can certainly not constrain regions where there are little data. Global tomographic models have little detailed resolution. High-frequency refection, scattering, and coda studies paint a much more complex picture of the mantle than is available from long-period waves [e.g., Thybo and Perchuc, 1997; Shearer and Earle, unpubl.].

Color 2D cross-sections are particularly ambiguous. Although certainly vivid - and impressive to nonspecialists-they are not "overwhelming, compelling or convincing" evidence; they can be overinterpreted. They cannot do justice to the information content of a typical tomographic study. There are also issues of physical, geodynamic, and petrological interpretations: For example, are "blue" regions of the "lower mantle" - even if real- unambiguous indicators of cold, dense material that started at the Earth's surface? This again is a mineral physics and scaling issue. Can global tomography-or midocean ridge basalts-reveal the true heterogeneity of the mantle or is it averaged out? These are sampling issues.

\subsection{Ways out of the Crisis, if There Is One}

Any inverse problem, including seismic tomography, must deal with limitations dictated by the distribution and quality of the data, sampling theory, and trade-offs between diverse structures within the Earth; it is likely that the Earth possesses a substantial component in the null-space of any mix of data [e.g., Shapiro and Ritzwoller, 2004]. This is also true for isotope data and box models. Methods are available to control the overinterpretation of sparse data, but these guarantee neither physical acceptability of the resulting model nor a model that resembles the real Earth. These limitations are fundamental. Producing realistic, physically plausible Earth models and interpretations requires physical constraints to be applied [Shapiro and Ritzwoller, 2004] and an appreciation of what sparse coverage, smoothing, and overparameterization can do [Vasco et al., 1994; Boschi and Dziewonski, 1999].

Tomographic images are often interpreted in terms of an assumed velocity-density-temperature correlation; e.g., high shear velocity (blue) is attributed to cold, dense slabs, and low shear velocity (red) is interpreted as hot, rising, lowdensity blobs. Many factors control seismic velocity, and some do not involve temperature or density [see, for example, Chapters 5-7 and 13-16 in Anderson, 1989a]. Cold, dense regions of the mantle can have low shear velocities [e.g.,
Trampert et al., 2004; Presnall and Gudfinnsson, 2005]. Changes in composition or crystal structure can lower the shear velocity and increase the bulk modulus and/or density, as can verified by checking any extensive tabulation of elastic properties and densities of minerals (see Figure 1). Ishii and Tromp [2004], for example, found negative correlations between velocity and density in the upper mantle. If one drops the purely thermal and visual interpretations of tomographic cross-sections, a resolution of some of the paradoxes is apparent. The tomographic interpretations that precipitated the perceived crisis are not unique.

For reviews of the situation regarding seismic modeling, including uncertainties and limitations, see Ritsema et al. [1999], Vasco et al. [1994], Boschi and Dziewonski [1999], Dziewonski [2004, 2005], Julian [2004], Shapiro and Ritzwoller [2004], Lay [2005], and Ritsema [2005]. Bottom line: The mantle is not similar to the one- and two-layer 1D structures that underlie the standard models, and temperature is not the sole parameter controlling seismic velocities.

\section{PHILOSOPHY AND GROUND RULES}

The present contribution is the flip-side of a series of recent review, comment, and synthesis papers that defendor present modifications to- the standard models, without changing the basic assumptions [e.g., van der Hilst et al., 1997; AvdH; Kellogg et al., 1999; Helffrich and Wood, 2001; DePaolo and Manga, 2003; van der Hilst, 2004]. These represent one particular train of thought - and a limited parameter and assumption range - regarding mantle structure and evolution, with an emphasis on mass-balance, heat budget, visual tomography, and convection and mixing simulations. For a review of the pros and cons of this class of models, see van Keken et al. [2002]. Recognition of the nonuniqueness of the tomographic and geochemical models is the first step in resolution of the crisis. Other elements that have been missing in recent discussions of mantle structure and evolution are physical plausibility, initial conditions, petrology and mineral physics, and to some extent, statistics-particularly the central limit theorem. Physics of materials at high pressure, thermodynamics, the initial state of the mantle, scaling, and sampling theory are discussed later. These topics can be grouped into themes of self-gravitation (pressure), self-consistency (thermodynamics), and self-organization (thermochemical convection in a gravity field). Pressure can make gravitational stratification irreversible and the deeper layers inaccessible. This possibility alone can resolve many of the geochemical paradoxes; that is, there can be hidden and inaccessible regions. Sampling theory vs. convective mixing has been discussed elsewhere [Meibom and Anderson, 2003]. 
A major advance has recently been made by Trampert et al. [2004], using probabilistic tomography and the integration of mineral physics and seismology. According to these authors, and Steve Grand [personal communication, 2005], temperature variations are much weaker than-or even the opposite of - those inferred from shear velocity by using conventional scaling relations. In the deep mantle, the correlation between shear velocity and temperature is weak, and large features of low shear velocity may be due to variations in silicon and iron content or to the spin-state of iron but not to high temperatures [see also Ishii and Tromp, 2004]. These features are not buoyant-or strongly buoyant-as was assumed in the past. The size of these features and the lack of a strong thermal signature, which is not predicted by the standard models, can be understood by considering the effect of pressure on thermal properties.

\section{THEMES}

\subsection{Pressure and Chemical Stratification}

Pressure decreases interatomic distances, which has strong nonlinear effects on such properties as thermal expansion, conductivity, melting point, and viscosity; on the interpretation of seismic images; and on the possibility of chemical stratification of the mantle. The range of plausible lithologies in both the upper mantle and lower mantle is such that there may be only very small differences in the seismic velocities [e.g., Zhao and Anderson, 1994; Lee, 2003; see also Figure 1], particularly at high pressure. Even eclogite and peridotite can have similar seismic velocities over some depth intervals. Various candidate lower mantle assemblages have almost identical elastic properties. Thus, compositional changes and interfaces are hard to detect-one reason why some investigators have assumed they do not exist. Some arguments for whole-mantle convection are based on the absence of obvious seismological evidence for layering and thermal boundary layers (TBLs), or on the presence of broad highvelocity bands below $650-\mathrm{km}$ depths (see Appendix 1). Note that chemical discontinuities can have similar shear velocity on both sides and that the shear velocity can drop across a density jump discontinuity.

It has recently become possible to resolve density from seismic data and to separate the effects of temperature and composition [Trampert et al., 2004; Ishii and Tromp, 2004]. The basic assumption in many tomographic interpretations - that low seismic velocity is always a proxy for high temperature and low density-is not valid. There is no correlation in properties between the upper mantle, midmantle, and lower mantle and no evidence for either deep slab penetration or continuous plume-like low-velocity upwellings
[Becker and Boschi, 2002; Ishii and Tromp, 2004, Trampert et al., 2004] - consistent with chemical stratification [Wen and Anderson, 1995, 1997]. Whether the stratification is primordial or stable requires information outside the realm of seismology. Chemical stratification of the mantle-both reversible and irreversible - depends on the initial conditions and the variation of physical properties with temperature and pressure. These, plus evidence for stratification, are treated below.

\subsection{The Initial State}

Although a homogeneous mantle with constant properties is the simplest imaginable assumption, no one has simply explained how the mantle may have arrived at such a state, except by slow, cold, homogeneous accretion. This is an unstated assumption in the standard models. The accretion of Earth was more likely to have been a violent high-temperature process that involved repeated melting and vaporization, and the probable end result was a hot, gravitationally differentiated body.

The assumed starting composition for the Earth is most plausibly based on cosmic abundances, e.g., the refractory parts of carbonaceous, ordinary, or enstatite chondrites [Ringwood, 1966; Anderson, 1989a; Agee, 1990; Javoy, 1995]. These compositions predict that the lower mantle has more silicon than the olivine-rich buoyant shallow mantle and that only a small fraction $[\sim 7 \%]$ of the mantle can be basaltic [e.g., Anderson, 1989a, Chapter 8]. The pyrolite model initially assumed $20-25 \%$ basalt. Isotope-based models do not constrain the major elements.

The volatile components still in the Earth were most likely added as a late veneer after the planet had cooled to the point where it could retain volatiles. The other choices for starting compositions-considering the standard models - are (1) undegassed volatile-rich ("primordial") components with abundances of both refractory and volatile elements, including noble gases, similar to unfractionated undegassed carbonaceous chondrites [Kellogg and Wasserburg, 1990], and (2) whole-mantle compositions dictated by upper-mantle peridotites (the pyrolite and the whole-mantle convection model of Ringwood [1975]). The first option evolves to the standard model upon degassing and crustal extraction from the upper mantle; the lower mantle remains fertile and gasrich. The second option is equivalent to a particularly fertile, whole-mantle convection model, with slabs sinking readily into the deep mantle.

Melting and gravitational differentiation during accretion sets the stage for mantle evolution, including the distribution of radioactive elements. This step is often overlooked in geochemical and geodynamic models, which often start with 
a homogeneous mantle, or even a cold, gas-rich mantle. The initial temperatures may have been forgotten, but the stratification of major and radioactive elements can be permanent. An excellent summary of initial conditions from a petrological point of view is given by Ringwood [1966, 1979].

\subsection{Petrological Models}

Mantle models based on accretional differentiation and petrology [e.g., Birch, 1952; Anderson, 1983, 1987a; Agee, 1990; Armstrong, 1991; Gasparik, 1997] are more complex than one- and two-layer models [e.g., Coltice and Ricard, 1999; Helffrick and Wood, 2001], hybrid models [e.g., AvdH], and convection models that ignore petrology, the effects of pressure, and early and irreversible gravitational differentiation. High-resolution seismological techniques involving reflected and converted phase and scattering are starting to reveal the real complexity of the mantle.

In addition to the neglected issues of pressure, petrology, and initial conditions, some other assumptions also distinguish the standard models from alternative models. Some of these are discussed below.

\subsection{Sampling or Stirring?}

Assumption: The "convecting" upper mantle is efficiently stirred and homogenized.

Corollary: Non-MORB and enriched magmas come from the lower mantle.

The survival of layers, blobs, and reservoirs and the possible entrainment and homogenization by vigorous convective stirring are issues in all current models of mantle structure and evolution. At high Rayleigh numbers, inhomogeneities in the mantle may be stretched, thinned, folded, and stirred, the usual explanation for homogeneous MORB. Inefficient stirring is used to explain "anomalous" basalts in the single layer and mantle-blob schemes of mantle convection [Becker et al., 1999; Coltice and Ricard, 1999]. The usual assumption in these calculations is whole-mantle convection, uniform density and viscosity, very high Rayleigh number $\left(10^{7}-10^{8}\right)$, no pressure effects, steady-state, unidirectional stirring, Newtonian rheology, long stirring times, and no plates; i.e., chaotic mixing is encouraged. Often the calculations are done in 2D Cartesian coordinates with uniform surfaces, no continents, and no internal heating [e.g., van Keken et al., 2002]; the fluid and the surface are often not free to self-organize. The experimenter has a great deal of control on the outcome. An important issue, therefore, is, "What is the Rayleigh number of the mantle and is it really so easily homogenized by convection?"
Mantle convection is most often treated with the simplest possible assumption, the Boussinesq equations. These assume that volume $(V)$ is a function only of temperature $(T)$ and that all other properties are independent of $T, V$, and pressure $(P)$, even those that explicitly depend on $V$. Results of such simulations, and of laboratory experiments, are of pedagogic interest but are not relevant to the behavior of the mantle. But scaling relations can be used to predict general behavior such as layering vs. mixing. For example, if the intrinsic density jump across a chemical interface is greater than the density change that can be created by thermal expansion at that depth, then the stratification will probably be stable and irreversible. If the effects of pressure on material properties and the Rayleigh number-and original density stratification-are ignored, it is more likely that the mantle can be well-stirred and homogenized. In a convectively layered mantle with volume dependent properties, the effective Rayleigh number is low and chemical differentiation (gravitational stratification) rather than homogenization must be considered a possible outcome. In the standard two-box model, stratification is due to removal of the crust from the upper layer and is unrelated to accretion or density stratification.

The assumption that the entire upper mantle is efficiently stirred and homogenized, or that whole-mantle convection must destroy chemical heterogeneities, underlies some of the geochemical paradoxes and provides the rationale for recent hybrid models. Left to itself and allowed the necessary degrees of freedom - the essence of self-organization - the mantle may behave in a way inconsistent with imposed boundary conditions, stirring history, and material parameters. Even if the mantle is convecting, the isotopic diversity of magmas may not be an issue of solid-state stirring, layering, or entrainment [Zindler et al., 1984; Gerlack, 1990; Meibom and Anderson, 2003]. Some stirring calculations give mixing times much greater than sampling times [Olsen et al., 1984] and much greater than the characteristic time of $1 \mathrm{Ga}$ assumed by Albarède [2001]. Another standard assumption is that homogeneous basalts require a homogeneous source. The alternative to homogenization by convection is magma blending during the sampling and eruption stage [Anderson, $1989 \mathrm{a}$, p. 231$]$ or the extraordinarily powerful central limit sampling theorem [Anderson, 2000, 2001; Meibom and Anderson, 2003], which explains why chemical diversity is rare along spreading ridges.

\subsection{Distribution of Radioactive Elements}

Assumption: The lower mantle is primordial, undegassed, or less degassed compared with the upper mantle; it is enriched or undepleted in $\mathrm{U}$, Th, and $\mathrm{K}$. 
Mass-balance and thermal constraints are consistent with the view that the radioactive elements are strongly concentrated into the crust and upper mantle [Birch, 1952; Clark and Turekian, 1979; Anderson, 1989a, 2002a]. Note: The upper mantle-a seismological concept-is not equivalent to "the MORB-source", "the convecting mantle", "the depleted upper mantle" (DUM) of the standard models; the "upper mantle" of recent geochemical models-above $670 \mathrm{~km}$-is not the same as the classical upper mantle of seismology: above 1,000-km depth [Bullen, 1947; Birch, 1952].

There is a rapid decrease in concentrations of radioactive elements from the upper crust $(U=2.8 \mathrm{ppm})$ through the midcrust (1.6 ppm) and the lower crust $(0.2 \mathrm{ppm})$ to lithospheric xenoliths $(0.04-0.12 \mathrm{ppm})$ [Rudnick and Fountain, 1995]. Clark and Turekian [1979] suggested that a general exponential decrease with depth in the mantle with a characteristic scale of $1,000 \mathrm{~km}$ would satisfy the thermal constraints and that essentially no radioactive elements may be present in the deep mantle. This is a plausible but not unique interpretation, but it does contradict the common view that heat flow and heat production requires that the deep mantle is rich in $U$, Th, and $\mathrm{K}$. The "missing" $\mathrm{U}$, Th, and $\mathrm{K}$ may be in the upper mantle: in EMORB components, in kimberlite, and in other enriched components, some recycled [Anderson, 1989a; Chapter 8]. Others have proposed deep radioactiverich layers [Kellogg et al., 1999], assuming that the MORB source (depleted MORB endmember plus U- and Th-free peridotite) fills up 'the upper mantle'. Some enriched components in the mantle-kimberlites, for example-are so enriched that if they occupy only a small fraction of a percent of the upper mantle, they can account for the missing elements and, at the same time, account for the fact that MORB is not exactly complementary to the continental crust.

The conjecture that there are no enriched components in the upper mantle - that the whole upper mantle is uniform and depleted-is the source of some of the geochemical paradoxes. Paradoxes in mantle dynamics and thermal evolution can be traced to the assumption that the lower mantle has high concentrations of U, Th, and K [e.g., Bunge et al., 2001].

A plausible alternative layered model-with none of the above paradoxes - has almost all of the radioactivities in the crust and upper mantle [e.g., Chapter 8 in Anderson, 1989a]. Secular cooling also occurs mainly in the upper mantle; the existence of deep and large TBLs depends on the balance of heating and cooling of the upper layers. The standard model with strong heating from the core, little heating in the upper layer, and strong heating and little secular cooling in the deep layer, will develop a strong TBL at the base of "the upper-mantle" and possibly one at the core-mantle boundary; this is a necessary but not sufficient condition for plume formation.
The amount of ${ }^{4} \mathrm{He}$ escaping through the surface is only about $5 \%$ of that thought to be generated by radioactive decay [O'Nions and Oxburgh, 1983]. More than 20\% of the Earth's ${ }^{40} \mathrm{Ar}$ is not in the atmosphere [Anderson, 1989a, p. 152]. Where are the missing noble gases stored? Some rocks dredged along the mid-Atlantic ridge are extraordinarily rich in gas, including ${ }^{3} \mathrm{He},{ }^{4} \mathrm{He}$, and ${ }^{40} \mathrm{Ar}$ [Sarda and Graham, 1990, and references therein]. Furthermore, such rocks show little indication of gas loss or contamination. Most MORB show fractionated noble gas patterns, consistent with degassing that occurred before sampling. If the gas-rich rocks are typical of undegassed MORB and if they represent $\sim 7 \%$ of the mantle, then they can account for the missing $\mathrm{Ar}$ and $\mathrm{He}$ and for the helium-heat flow paradox. Even normal degassed MORB have higher ${ }^{3} \mathrm{He}$ contents than OIB [Anderson, 1998].

\subsection{Distribution of Major Elements}

Assumption: The mantle is chemically homogeneous in the major elements, allowing whole-mantle convection.

Seismological and mineralogical properties can be compared in a variety of ways [e.g., Sammis et al., 1970; Anderson and Bass, 1984; Anderson, 1989a; Duffy and Anderson, 1989; Zhao and Anderson, 1994; Stacey and Isaak, 2000]. Conclusions using this 1D equation-of-state (EOS) approach are not robust; a variety of compositional models and temperatures for the lower mantle are consistent with the data [e.g., da Silva et al., 2000; Bunge et al., 2001; Stacey and Isaak, 2001; Kiefer et al., 2002; Lee et al., 2004], but this in itself explains some of the paradoxes such as the apparent absence - or invisibility - of compositional discontinuities. Equations-of-state modeling (1D) and inspection of a tomographic cross-section (2D) are tools that are much too blunt to "prove" that the lower mantle has the same (or different) chemistry as the upper mantle, even for the major elements. Mass-balance and EOS calculations with major elements are permissive of bulk chemistry changes at $400-, 650$-, or $1,000-\mathrm{km}$ depth but do not require these.

Recent studies imply - or are consistent with-an ironrich high-temperature lower mantle [Stacey and Isaak, 2000; Lee et al., 2004; Mattern et al., 2005] or a lower layer that is chemically different from the upper mantle. The possibilities that iron is concentrated into a postperovskite phase and a low-spin iron-rich phase complicate matters still further and have not yet been incorporated into EOS modeling. High thermal conductivity - lattice and/or radiative - in the deep mantle may allow core heat to be conducted through the lower TBL without plume formation. This depends on the local Rayleigh number at the base of the mantle, an approach that is developed below. 


\subsection{Self-Consistency and Self-Organization}

Assumption: Convection models cannot maintain sharp interfaces in the mantle...convective mixing should take place with a characteristic time of less than 1 Gy and should essentially wipe out mantle heterogeneities.

Thermal convection is a self-organized thermodynamic system far from equilibrium in a gravity field and is sensitive to initial conditions and slight changes in conditions or parameters [Tackley, 2000; Anderson, 2002a,b]. The mantle is a $3 \mathrm{D}$ object, and convection and plate tectonics are $3 \mathrm{D}$ processes. Tomographic cross-sections and convection in Cartesian boxes or with enforced axes of symmetry probably cannot reveal mantle processes. It is dangerous to generalize from a few oversimplified simulations [see, for example, Phillips and Bunge, 2005]. The above assumptions about the mantle depend on material properties, the mode of heating, and even the presence or not of a continent on the surface. The plausibility of chemical stratification depends on how-or if-pressure is treated. The role of mineral physics in mantle geodynamics is to provide a way to test hypotheses and to assure physical consistency in tomographic and convection studies. The parameters that control natural convecting systems at high-temperature and pressure are interrelated. Thermodynamic variables are often indiscriminately assumed to be constant, or to vary independently, ignoring thermodynamic constraints that preclude such assumptions [Schubert et al., 200I].

\section{SCALING}

The important parameters in mantle convection are density and expansivity. Because seismology measures seismic velocities, going from a tomographic model to a convective model requires scaling relations. Such relations, and the bridges they provide from mineral physics and petrology to seismology and geodynamics, are developed in the following sections. No scaling relations exist between isotopic properties and seismology, or between the colors on a tomographic cross-section and the direction of mantle flow, such as were assumed in developing the standard models-two-layer or whole-mantle.

\subsection{Scaling Relations in Seismology}

The relative behaviors of density, shear velocity, and bulk sound speed in the mantle are now being determined, and the results have implications for chemical and thermal structure [e.g., Trampert et al., 2001, 2004]. Prior to these developments it was common in seismology to attempt to infer density from the shear velocity and sometimes to assume or infer a relationship between seismic velocity and temperature. This approach was responsible for the initial revival of the whole-mantle convection hypothesis (see Appendix 1). It is still necessary, however, to use self-consistent thermodynamic relations.

\subsection{Scaling Relations in Geodynamics}

A measure of the vigor of convection and the distance from static equilibrium is the Rayleigh number, $\mathrm{Ra}$. This is also the scaling parameter for the effect of size on the system. Estimates of Rayleigh numbers for the mantle often do not take into account the effect of pressure on physical properties or of layering. In a spherical shell, convection occurs spontaneously when $\mathrm{Ra}$ exceeds about 2,000 [Chandrasekhar, 1961]. Chaotic convection and efficient mixing-implicit in the "convecting mantle" scenario of the standard model--are thought to require $\mathrm{Ra}$ of $>10^{7}$, which is very far from static or conductive equilibrium. Can realistic mantle models yield such values?

Mantle convection and mixing calculations with $\mathrm{Ra}$ of $10^{7}$ or higher [e.g., Bunge et al., 2001] are, in effect, assurning that the zero-pressure values of thermal and transport properties are maintained throughout the mantle and that whole-mantle convection operates. If one instead uses values estimated for the base of the mantle [Tackley, 1998], one derives a value of only about 4,000 for whole-mantle convection, barely twice the critical value. The Rayleigh number depends on the thickness of the convection layer cubed. Therefore, a chemically (or convectively) layered mantle will have a lower effective Rayleigh number than will a chemically homogeneous mantle with whole-mantle convection, and stirring will be inefficient. If the lower $1,000 \mathrm{~km}$ of the mantle is convectively isolated, $\mathrm{Ra}$ for that region drops to 500 . It is thus possible that the deep mantle convects sluggishly, episodically, or not at all. In systems involving a pressure gradient, a single Rayleigh number is not an adequate description of convective style.

\subsection{Volume as a Scaling Parameter}

The main effects of pressure, temperature, and phase changes on physical properties are volume changes. The thermal, elastic, and rheological properties of solids depend on interatomic distances, or lattice volumetric strain, and are relatively indifferent as to what causes the strain $(T, P$, or crystal structure) [Birch, 1952, 1961; Anderson, 1967a, 1987a, 1989; Anderson and Anderson, 1970]. Intrinsic temperature effects are those that occur at constant volume. Quasiharmonic approximation is widely used in mineral 
physics but not in seismology or geodynamics, where less physically sound relationships are traditionally used. This is ironic since some of the earliest and most fundamental contributions to this field were made by geophysicists [e.g., Thomsen, 1972; Davies, 1974].

A parameter that depends on $P, T$, phase $(\phi)$, and composition (C) (within limits, e.g., constant mean atomic weight) can be expanded as

$$
\mathrm{M}(P, T, \phi, \mathcal{C})=\mathrm{M}(V)+\varepsilon
$$

where $\varepsilon$ represents higher-order intrinsic effects at constant molar $V$. This is the basis of Birch's Law [Birch, 1961], the seismic equation of state [Anderson, 1967a, 1987a], laws of corresponding states, and quasiharmonic approximations. Lattice dynamic parameters and thermodynamic and anharmonic parameters are interrelated by way of volume. In some cases, the intrinsic effect of temperature is important, but the quasiharmonic approximation is a step away from the Boussinesq and related approximations that ignore the effects of volume change on most physical properties or that combine pressure and temperature effects in thermodynamically inconsistent ways.

\subsection{Beyond Boussinesq}

The effect of volume changes on thermodynamic properties are determined by dimensionless parameters. Scaling parameters for volume-dependent properties [Anderson, 1987a, 1989a] can be written as power laws or as logarithmic volume derivatives about the reference state:

$\begin{array}{ll}\text { Lattice thermal conductivity } & d \ln \kappa_{\mathrm{L}} / d \ln V \sim 4 \\ \text { Bulk modulus } & d \ln \mathrm{K}_{\mathrm{T}} / d \ln V \sim 4 \\ \text { Thermal expansivity } & d \ln \alpha / d \ln V \sim-3 \\ \text { Viscosity } & d \ln V / d \ln V \sim 40-48\end{array}$

These are semiempirical, numerical values estimated from laboratory and geodynamic measurements. Viscosity is an activated process and the above scaling is partly the volume effect on the preexponential and partly the effect on the activation volume [see Anderson, 1989a]. Estimates of viscosity can also be based on the homologous temperature assumption and the effect of compression on the melting point.

In the upper mantle, $T$ and phase changes mainly control $V$ variations, whereas in the deep mantle it is $P$, crystal structure, and (C) (including low-spin iron). $T$ is particularly important in the upper mantle where the coefficient of thermal expansion is large and increases with temperature and therefore with depth.

\subsection{Things That Do Not Scale With Volume}

Shear velocity, rigidity, viscosity, radiative conductivity, and seismic attenuation have intrinsic temperature, compositional, or structural dependencies in addition to volumedependent terms. They are not simple functions of density (see Figure 1). Shear velocity has an anelastic term that depends on frequency and microstructure. Rigidity has a strong intrinsic temperature term and is affected by iron substitution; the bulk modulus and molar volume are relatively insensitive to iron [Table 6.2 in Anderson, 1989a]. The pressure and temperature derivatives for bulk modulus fall into a narrow range for most minerals, whereas those for rigidity do not [Table 6.7 in Anderson, 1989a].

Viscosity is one of the most important--but most uncertain and most variable-parameters in mantle dynamics. However, the buoyancy parameter $\alpha \delta T$ is more important in discussions of chemical stratification. It takes a temperature perturbation of about $1,000 \mathrm{~K}$ to overcome a $1 \%$ density jump in the deep mantle. Viscosity decreases strongly over the depth intervals $1,000-1,400 \mathrm{~km}$ and $2,000-2,500 \mathrm{~km}$ [e.g., Forte and Mitrovica, 2001]. The former interval also has anomalous thermal and $\mathrm{FeO}$ gradients [Mattern et al., 2005] and seems to be a fundamental boundary, even barrier, in the mantle [e.g., Wen and Anderson, 1997].

\section{APPLICATIONS}

The specific volume at the base of the mantle is $64 \%$ of that at the top [Dziewonski and Anderson, 1981]. Compression, composition, and phase changes, and to some extent temperature, are all involved. Although volume scalings such as the Debye theory and the quasiharmonic approximation are strongly grounded in classical physics, they have not been implemented in mantle convection codes. The scaling theory reviewed above will be applied to a few situations relevant to the deep mantle: the Rayleigh number, the thickness and growth time of a deep thermal boundary layer, the "detectability" of chemical interfaces, and the possibility of irreversible chemical layering.

\subsection{Rayleigh Numbers}

The TBL thickness of a fluid cooled from above or heated from below grows as follows:

$$
\mathrm{h} \sim(\kappa t)^{1 / 2}
$$

where $\kappa$ is thermal diffusivity, and $t$ is time. The TBL becomes unstable and detaches when the local or sublayer Rayleigh number 


$$
\mathrm{Ra}_{\mathrm{c}}=\alpha g(\delta T) \mathrm{h}^{3 / \kappa \nu}
$$

exceeds about 1,000 [Howard, 1966; Elder, 1976], where $g$ is acceleration due to gravity; $v$ is kinematic viscosity, and $\delta T$ is the temperature increase across the TBL.

The combination $\alpha / \kappa v$ decreases with $V$ decreases, thereby lowering $\mathrm{Ra}_{\mathrm{c}}$ at high $P$ or low $T$. Compressible flow, temperature-dependent viscosity, and internal heating make $\delta T$ across a deep TBL less than $\delta T$ at the surface [Tackley, 1998; Lenardic and Kaula, 1994], much less if there are intervening boundary layers. Because $\alpha \delta T$ decreases with depth, irreversible density stratification is favored, even for small intrinsic density contracts. The viscosity at the base of the mantle is probably higher than in the asthenosphere, and the drop in viscosity across the TBL is less.

The local Rayleigh number controls TBL thickness. At the surface the issue is complicated because of water [Hirth and Kohlstedt, 1996], intrinsic buoyancy, and the fact that $\alpha, \kappa$ and $v$ are strongly $T$-dependent. For parameters appropriate for the top of the mantle, treated as a constant viscosity fluid, the surface TBL becomes unstable at a thickness of about $100 \mathrm{~km}$ [Elder, 1976]. The time-scale is about $10^{8}$ years, approximately the lifetime of surface oceanic plates.

\subsection{Tomography}

The implication of the volume scaling plus the role of anelasticity is that temperature effects are much less important in the deep mantle than at the surface. At high-pressure, temperature has little effect on density and other properties that depend on density. Chemical- and phase-changes, anisotropy, and fluids should dominate seismic velocity variations; this changes the usual visual and thermal interpretations of seismic images.

The changes that control upper mantle properties are melting, anelastic, mineralogical, chemical, and thermal [e.g., Goes et al., 2000; Lee, 2003; Perry et al., 2003]. Upper mantle chemical and temperature gradients create a lowvelocity, low-viscosity, high-attenuation, and low-conductivity zone, usually equated with the asthenosphere, at depths of $\sim 100$ to $200 \mathrm{~km}$. At greater depths, the temperature gradient and the effect of temperature on $V$ and elastic properties become small but pressure continues to increase. At very high pressures, thermal expansivity is low, and composition and mineralogy control lattice volume. Composition, silicate and metallic melts, and phase changes (including the lowspin transition in $\mathrm{FeO}$ and the postperovskite phase change) become the important controls on $V$, conductivity, buoyancy, and seismic parameters. Activated and quantum effects have additional (intrinsic) temperature dependencies. Purely thermal upwellings are expected to have low bulk modulus, low compressional velocity, and low density. Such is not the case for the large lower-mantle features [Ishii and Tromp, 2004; Trampert et al., 2004]; they have the appropriate dimensions to be thermal in nature but resemble more a chemically dense layer at high pressure, i.e., large-scale marginally stable domes with large relief. These domes may have neutral density or may be slowly rising or sinking. In any case, they will affect the geoid, the dynamic surface topography, and the relief on other chemical boundaries, even if they are isolated. $\mathrm{D}^{\prime \prime}$ may be a very dense - probably iron-rich - layer, and the overlying "layer", $D^{\prime}$, would be a less dense region trapped between $D^{\prime \prime}$ and the rest of the lower mantle. Stratification may have been established during accretional melting of the Earth [Anderson, 1989a; Agee, 1990; Armstrong, 1991] by downward drainage of dense melts, residual refractory phases, and iron partitioning into phases that may include postperovskite [Murakami et al., 2004], low-spin iron-rich oxides and sulfides [Gaffney and Anderson, 1973; Li et al., 2004], and intermetallic compounds. The large, low-shearvelocity features are more appropriately called "domes", a geologically descriptive term, than "megaplumes", which implies a thermal, active upwelling with low-density and low-bulk modulus. The existence of large lateral changes in chemistry and lithology makes suspect all attempts to infer composition and temperature from ID mantle models such as PREM.

\subsection{Thermal Boundary Layers}

A homogeneous fluid with constant properties, heated from below, will develop symmetric upper and lower thermal boundary layers. Downwellings and upwellings from the boundaries have the same dimensions and time constants. However, because the upper, middle, and lower thirds of the mantle have quite different viscosities, spectral and spatial characteristics, and correlations with plate reconstructions, the concept has developed of a tripartite mantle [Anderson, 2002a] in which the upper $1,000 \mathrm{~km}$ is the active and accessible layer. The boundaries are much more subtle than phase change discontinuities. Whether these distinctively different tomographic regions differ in intrinsic chemistry and whether they can exchange material are matters of current debate. The domes in the lower third of the mantle-the abyss - have dimensions much larger than upper mantle slabs, consistent with the scaling. The small ultra-low-velocity zones [Garnero and Helmberger, 1995] are here interpreted as dense regions containing core or mantle fluids or reaction products; they are probably very iron-rich.

If the whole lower TBL goes unstable, we have a diapiric plume. Scaling relations show that these will be huge, slow to develop, and long-lived. When a thin low-viscosity, 
low-density layer at the CMB feeds a plume head, we have cavity plumes with large bulbous heads and narrow tails. Temperature-dependence of viscosity is required. Mantle flow driven by cooling of the top TBL and internal heating makes it difficult for cavity plumes to form-this is one of the plume paradoxes [Nataf, 1991]. Pressure broadens considerably the dimensions of diapir plumes and cavity plume heads. It is this pressure-broadening that makes intuitive concepts about plumes [e.g., DePaolo and Manga, 2003], based on unscaled laboratory simulations, implausible for the mantle.

A solution to this plume paradox was investigated by Lenardic and Kaula [1994]. The solution itself is paradoxical. The condition for a cavity plume is created by destabilizing the upper TBL, which sinks, thins, and cools the lower TBL. Plume formation is triggered from above rather than from an instability in the boundary layer itself as in normal plume theory. In effect, plumes are "splashed out" by impacting cold slabs. However, in general, the effects of temperature are reversed by pressure, and only broad domes or diapirs can form at depth.

\subsection{The Lower Thermal Boundary Layer}

The presence of a lower TBL and the need to power the dynamo do not require that plumes exist or that they have the properties assigned to plumes in the current literature. The key questions are (1) Are the lattice and radiative conductivities of the lower mantle high enough to conduct heat out of the core without formation of TBL instabilities? (2) Are the dimensions and timescales of these upwellings, if they exist, of the order of hundreds of kilometers and tens of millions of years? (3) Do they rise to the surface? (4) Can they create the sorts of melting anomalies seen at the surface? and (5) Is the lower TBL stabilized by high intrinsic density? The neglect of pressure and scaling effects is responsible for the widely held misconception that narrow rapidly upwelling cylinders are required by boundary layer and dynamo theory [e.g., DePaolo and Manga, 2003]. This misconception is maintained by unscaled laboratory injection experiments and Boussinesq computer simulations [e.g., Cordery et al., 1997]. The core can get rid of its heat by mechanisms other than $\sim 200-\mathrm{km}$-wide plumes rapidly rising to the surface. A TBL can be stable if its Rayleigh number is subcritical or if the layer is dense enough.

The critical dimension of lower-mantle thermal instabilities, ignoring radiative transfer, is predicted from the above considerations to be about 10 times larger than at the surface, or about $1,000 \mathrm{~km}$. This is consistent with seismic tomography [Hager et al., 1985; Hager and Clayton, 1989; Tanimoto, 1990; Gu et al., 2001] and with compressible flow calculations from depth-dependent properties [Tackley, 1998]. If there is an appreciable radiative component to the conductivity, or a chemical component to the density (i.e., chemical stratification), then the scale-lengths can be much greater. Large-scale thermochemical features have been inferred from seismology [Ishii and Tromp, 2004; Trampert et al., 2004] and simulated with non-Boussinesq convection calculations [Tackley, 1998].

The timescale of deep thermal instabilities scaled from the upper mantle value is $\sim 3 \times 10^{9}$ years. Radiative transfer and other effects may increase thermal diffusivity, further increasing the time required to form an instability. The surface TBL cools rapidly and becomes unstable quickly. The same theory, scaled for the density increase across the mantle, predicts large and long-lived features above the core. This - plus chemical stratification - is the most dramatic effect of pressure and volume scaling. Further implications are that the long-wavelength geoid and the rotation axis are very stable over time [e.g., Anderson, 1989a, Chapter 12] and that long-lived hot and cold regions of the lower mantle are more likely to influence the temperature of the mesosphere and upper mantle than vice versa. There is no evidence that the large low-shear-velocity features cause the $\mathrm{TZ}$ to thin (one indication of heating)

If the abyss represents one-third of the mantle, it will have an reduction in Ra due to this effect alone by a factor of 27 relative to a reference state of whole-mantle convection. A similar reduction is accomplished by viscosity increase alone. Together, these decrease the deep mantle Ra by about $10^{3}$, compared with whole-mantle, constant-property values. There may also be other chemical boundaries in the mantle [Anderson, 1979, 2002a] that would further reduce $\mathrm{Ra}$ and the $\delta T$ across TBLs. The predicted large-scale longevity and sluggishness of deep mantle features are not entirely due to high viscosity. Low $\alpha$ at high $P$ means that intrinsically dense layers may be permanently trapped; moderate jumps $(\sim 1 \%$, depending on $\delta T)$ in density between layers in the mantle can stabilize chemical layering [Tackley, 1998; Anderson, 2002a]. Unreasonably high mantle temperatures do not occur in these trapped layers if most of the radioactivity is in the crust and upper mantle [Anderson, 1989b; Anderson, 2002a]. Heat can also be conducted more efficiently at high $P$.

\subsection{Relation to Plume Heads}

The scales of lower mantle thermal diapiric instabilities are much larger than those quoted for plume heads. The volumes of plume heads are often assumed to be related to the sizes of large igneous provinces-a circular argument-or to the thickness of $D^{\prime \prime}$, assuming it is purely thermal. The Boussinesq approximation also favors small plume heads. If 
the thickness of $\mathrm{D}^{\prime \prime}$ is controlled by compositional layering or phase changes [Lay et al., 1998] then one must look elsewhere for the scale of lower mantle thermal instabilities. $D a$ Silva et al. [2000] found that the thermal gradient in much of the lower mantle is superadiabatic. If this is interpreted as evidence for a TBL, the layer is more than $1000 \mathrm{~km}$ thick, consistent with the scaling relations, and must have taken a long time to form. Heat is supplied to the CMB at less than 0.10 the rate at which heat is removed from the surface boundary layer [e.g., Christensen and Tilgner, 2004], so deep TBL instabilities are slow to form. Nevertheless, if there is little radioactivity in the deep mantle [e.g., Anderson, 1983], the bottom heating may dominate.

\section{STRATIFIED MANTLE?}

The conflict, confrontation, and crisis that permeate the isotopic literature may be a chimera. The whole-mantle convection/deep-slab penetration interpretation of tomographic cross-sections is neither unique nor robust [Boschi and Dziewonski, 1999; Cizkova et al., 1999; Davaille, 1999; Hamilton, 2002; Cizkova and Matyska, 2004; Dziewonski, 2004,2005 ] and it is inconsistent with geophysical evidence more broadly defined. Petrology-based models tend to be gravitationally stratified, with buoyant olivine-rich regions at the top, dense perovskite- and iron-rich features at depth, and low-melting-point eclogitic materials-among other things-at intermediate depths [e.g., Anderson, 1983; Agee, 1990] (see Figure 1). In these models, the midmantle, upper mantle, and crust are chemically complementary to the deep mantle and to each other. Abrupt seismic discontinuities are not necessarily isotope or reservoir boundaries. What distinguishes this class of models from the others is gravitational stratification by density-which is reversible in the upper mantle-and upward concentration of volatile and LIL, including $\mathrm{U}, \mathrm{Th}$, and $\mathrm{K}$. Another distinction is that the deeper layers are not necessarily accessible to surface volcanoes. Plate tectonics and geochemical cycles may be entirely restricted to the upper $\sim 1,000 \mathrm{~km}$, where thermal expansion is high and melting points, viscosity, and thermal conductivity are low.

This class of layered models does not have the paradoxes associated with the standard models or with QCT interpretations, and is consistent with the effects of volume changes discussed in this chapter. The presence of inaccessible (residual) regions is consistent with various mass-imbalance calculations that are paradoxical in the standard models, or with the standard assumptions. Even the crust and the continental lithosphere have managed to stratify themselves by their intrinsic density [Rudnick and Fountain, 1995; Lee et al., 2003].
The seismic velocities of plausible materials in the mantle differ little from one another, even if the density contrasts are adequate to permanently stabilize the layering against convective overturn [see Anderson, 2002a, and eclogite vs. peridotite in Table 1 of Chapter 3 in Anderson, 1989a]. Since chemical discontinuities can be almost invisible to 1D seismology, compared to phase-changes, and since even small chemical density contrasts can stratify the mantle, the possibility must be kept in mind that there may be multiple chemical layers in the mantle, some of which may be subtle (e.g., see Figure 1). The major seismic discontinuities in the mantle are due to mineralogical and phase-changes, not chemical changes, but this does not rule out a chemically heterogeneous mantle.

\subsection{Chemical Discontinuities?}

The claimed lack of evidence for global seismic interfaces between $650-\mathrm{km}$ depth and D" is sometimes taken as evidence against chemical stratification. Actually, a systematic search for mantle reflections [Deuss and Woodhouse, 2002] found a continuum of robust reflectors between 750- and $1,200-\mathrm{km}$ depth. Their reflection histogram can be explained by three phase-changes (at average depths of 400,520 , and $650 \mathrm{~km}$ with variations of $40 \mathrm{~km}$ ) and three chemical boundaries (at average depths of 220,850 , and $1,100 \mathrm{~km}$ with variations of $100 \mathrm{~km}$ ). But the evidence for chemical stratification can also be subtle. Chemical discontinuities are sometimes discounted because of the perception that a fortuitous cancellation of chemical and thermal effects is required to explain their apparent absence. But small effects are predicted, as are large undulations in topography, consistent with the observations [e.g., Deuss and Woodhouse, 2002].

Phase-change discontinuities are, in general, easier to detect with seismology than chemical discontinuities. Different methods must be used for the latter. The evidence for large-scale stratification of the mantle includes tomographic patterns and spectra [e.g., Tanimoto, 1990; Scrivner and Anderson, 1992; Ray and Anderson, 1994; Wen and Anderson, 1995; Gu et al., 2001; Anderson, 2002a; Becker and Boschi, 2002; Trampert et al., 2004], dynamic topography and evidence for slab flattening, and apparent pileups [Fukao et al., 1992, 2001]. Support for a complication, discontinuity, or barrier near $900-\mathrm{km}$ depth is widespread [Whitcomb and Anderson, 1970; Tanimoto, 1990; Revenaugh and Jordan, 1991; Kawakatsu and Niu, 1994; Ritzwoller and Lavely, 1995; Wen and Anderson, 1995; Forte and Mitrovica, 2001; Shen et al., 2003; Mattern et al., 2004]. The tomographic structure of the mantle above the Repetti discontinuity - the upper mantle proper-correlates with present and past plate tectonics [Wen and Anderson, 1995; Becker 
and Boschi, 2002] and behaves as expected for fluid with a moderate Rayleigh number: cooled from above and driven by the plates and lithospheric architecture.

A variety of evidence therefore suggests there might be an important geodynamic boundary, possibly a barrier to convection at midmantle depths. This does not rule out thermal-coupling and apparent continuity across such boundaries [Cizkova and Matyska, 2004].

The lowermost $700-1,000-\mathrm{km}$ layer is rich in seismological 3D detail and differs from the overlying mantle in all respects [e.g., Garnero and Helmberger, 1995; Lay et al., 1998a; da Silva et al., 2000; Gu et al., 2001; Anderson, 2002a; Trampert et al., 2004]. A dense, trapped layer is most consistent with the observations and the physics. This part of the mantle is probably stabilized against convective overturn by the effects of pressure and composition and possibly by high thermal conductivity and by the low-spin transition in $\mathrm{FeO}$ [Badro et al., 2003]. The idea that the upper and lower thirds of the mantle might be chemically distinct and isolated is contested [e.g., Helffrich and Wood, 2001; DePaolo and Manga, 2003; van der Hilst, 2004] and is inconsistent with whole-mantle convection, deep slab penetration, plume, and homogeneous mantle ideas based on 1D Earth models, visual impressions of tomographic cross-sections through QCT, and Boussinesq or laboratory simulations. These approaches are becoming increasingly hard to defend.

\section{SUMMARY}

The petrological and mineral physics case for an inhomogeneous mantle and some sort of convective or chemical stratification is strong [e.g., Duffy and Anderson, 1989; Agee, 1990; Javoy, 1995; Gasparik, 1997; Wen and Anderson, 1997; Anderson, 2002a; Meibom and Anderson, 2003; Lee et al., 2004]. The seismological evidence is equally strong (Appendix 1), even though detail is washed out in the kind of frequencies and path-lengths used in global tomography. EOS modeling is ambiguous and nonunique and does not demand a homogeneous mantle. The scattering of high-frequency waves suggests a shallow heterogeneous mantle.

The kind of global chemical stratification that seems to be most consistent with all geochemical and geophysical evidence is essentially the inverse of the standard model and recent modifications of it [e.g., van der Hilst, 2004]. It involves a refractory, barren, inaccessible deep mantle (but not primordial, undegassed, or highly radioactive), with irregular chemical boundaries near 1,000- and 2,000$\mathrm{km}$ depths, and a passively convecting, but not mixing, upper mantle. Homogenization is achieved by sampling and melting, not by vigorous solid-state convection. The upper mantle is heterogeneous - both radially and laterally-in isotope geochemistry and fertility because of recycling and delamination. Most of the mantle is depleted in LIL and barren; only parts of the upper mantle are depleted and fertile. Magmas are homogenized at ridges where large volumes of mantle are processed continuously [Meibom and Anderson, 2003]. Large fertile blobs in the upper mantle, however, can create melting anomalies, even at ridges. The "missing" $\mathrm{He}$ and Ar may be in the upper mantle.

This kind of chemically layered model removes the objections that have been raised against some layered models and erroneously extended to all such models [e.g., Hager et al., 1985; Davies, 1988; Wen and Anderson, 1997; Coltice and Ricard, 1999; Helffrich and Wood, 2001; Schubert et al., 2001]. It appears to be a zero-paradox model.

Acknowledgements. I thank Adrian Lenardic, Russell Hemley, Jun Korenaga, and Anne Hofmeister for incisive reviews of an early draft and Raymond Jeanloz for discussions of related points. Frank Stacey, Geoffry Davies, Shijie Zhong, Robert Liebermann, and Yaoling Niu gave important advice for improvement and in correcting mistakes. Scott King's comments on the penultimate and ultimate versions were invaluable. Gillian Foulger, Seth Stein, Anders Meibom, Kanani Lee, and Jeroen Ritsema reviewed, and provided valuable input for, the revised version. Conversations with David Stevenson, Rob van der Hilst, Jeroen Ritsema, Jeroen Tromp, Bradford Hager, Richard O'Connell, Thomas Duffy, and Thorne Lay helped me identify problems and consolidate ideas, but mistakes and oversights, of course, are mine.

\section{APPENDIX 1. THE GEOPHYSICAL DATA}

The evidence against the standard model is not evidence against chemical stratification in general. However, because of the perceived crisis, some investigators have argued for a return to one-layer mantle models, ignoring a large body of other geophysical evidence. Geophysical data that have been cited in support of whole mantle convection include the following:

1. The long-wavelength tomographic structure of the lower mantle, and whole-mantle convection models with plausible velocity-density scalings and viscosity models, successfully explain the geoid [Hager et al., 1985; Hager and Clayton, 1989].

2. The bathymetry of the seafloor is explained by conductive cooling of the plate and whole-mantle convection [Davies, 1988].

3. Selected tomographic cross-sections show a few highvelocity features in the mantle below $650-\mathrm{km}$ depth. Intuitive scaling relations suggest that these may be cold, dense slabs [van der Hilst et al., 1997].

4. Scattering of high-frequency seismic energy is thought to be consistent with slab fragments in the lower man- 
tle and with whole-mantle convection [Helffrich and Wood, 2000].

5. The imbalance between heat flow and heat production is thought to require a deep mantle, rich in $\mathrm{U}$, Th, and $\mathrm{K}$.

6. The seismic properties of the lower mantle are consistent with pyrolite, the prototype upper-mantle rock.

Several of these interpretations rely on scaling relations and assumed mineral properties at high pressure. Problems with these interpretations are the following:

1. The geoid represents the combined effects of density variations in the interior of the mantle and the accompanying distortion of the boundaries (termed "dynamic topography") including the surface, the core-mantle boundary and any internal interfaces [e.g., Hager et al., 1985]. Both geoid and dynamic topography must be explained by the same model. Layered convection with a chemical boundary near $900 \mathrm{~km}$ deep, can explain both datasets [Wen and Anderson, 1997].

2. The inability of some layered models to explain bathymetry is due to the assumption that most surface heat flow is from radioactivity in the lower mantle. A chemically stratified mantle with most of the radioactive elements in the crust and upper mantle [Anderson, 1989a] does not suffer from this problem or a from a problem with lower mantle overheating. On the other hand, the large dynamic topography associated with whole-mantle convection affects the square-root age bathymetry relation. In the model of Wen and Anderson, dynamic topography is generated by density variations in the upper mantle and is of low amplitude. Ocean-floor bathymetry is dominated by cooling of the plate. Anomalous bathymetry is primarily due to shallow variations in density, not necessarily high temperature.

3. If the mantle is layered, tomography and the geoid can rule out shear-coupling between layers, but thermal or topographic coupling, or accidental correlations, cannot be ruled out. In layered convection simulations, thermal-coupling induces structures that visually resemble downwellings that penetrate the interface, but are not [e.g., Cizkova and Matyska, 2004]. Quantitative analysis of tomographic models and the history of plate subduction confirm the importance of a barrier near the depth of 900 $\mathrm{km}$ [Wen and Anderson, 1995].

4. Recent seismic scattering studies have been able to better isolate the source of the scattering. Most of the scattered energy comes from the upper mantle [Shearer and Earle, unpubl.; Baig and Dahlen, 2004] and can be attributed to slab fragments [e.g., Meibom and Anderson, 2003] or small-scale layering in the upper mantle. There are robust reflectors throughout the upper $1,200-\mathrm{km}$ of the mantle [Deuss and Woodhouse, 2002].
5. The imbalance between heat productivity and heat flow is a result of secular cooling and time lags associated with heat transport to the surface. Layered mantle models have larger time lags. Mass-balance calculations are consistent with most of the radioactivity, and with other LIL elements, being in the crust and upper mantle [Anderson, 1989a, Chapter 8; Rudnick and Fountain, 1995].

6. The seismic properties of the lower mantle are consistent with rocks quite different from pyrolite [Lee et al., 2004; Mattern et al., 2005], including rocks that are similar in major element chemistry to meteorites, and to meteorite compositions after the crust and upper mantle are removed.

\section{REFERENCES}

Agee, C. B., A new look at differentiation of the Earth from melting experiments on the Allende meteorite, Nature 346, 834-837, 1990.

Akimoto, S., High pressure transformations, Intern. Symp. Phase Transition Earth's Interior, Canberra, 1969.

Albarède, F., Plenary Lecture, European Union of Geosciences, 2001. (Www.theconference.com/JConfAbs/6/Albarède.html)

Albarède, F., and M. Boyet, A watered-down primordial lower Mantle, AGU, 84(46), Fall Meeting Suppl, Abstract, T21A-06, 2003.

Albarède, F., and R. D. van der Hilst, New mantle convection model may reconcile conflicting evidence, Eos 8(45), pp. 535, 537-539, 1999.

Albarède, F., and R. D. van der Hilst, Zoned mantle convection, Geochimica Cosmochimica Acta 66 (15A), A12-A12 Suppl., $2002 a$.

Albarède, F., and R. D. van der Hilst, Zoned mantle convection, Philos. Trans. Roy. Soc. A 360(1800), 2569-2592, 2002b.

Allegre, C. J., Chemical geodynamics, Tectonophysics 81, 109-32, 1982.

Allegre, C.J., Limitation on the mass exchange between the upper and lower mantle: The evolving convection regime of the Earth, Earth Planet. Sci. Lett. 150, 1-6, 1997.

Allegre, C., S. R. Hart, and J. F. Minster, Chemical structure and evolution of the mantle and continents determined by inversion of Nd and Sr isotopic data. I. Theoretical methods, Earth Planet. Sci. Lett. 66, 177-90, 1983.

Anderson, D. L., A seismic equation of state, Geophys. Jour. R. Astron. Soc. 13, 9-30, 1967a.

Anderson, D. L., Phase changes in the upper mantle, Science 157, 1165-1173, $1967 \mathrm{~b}$.

Anderson, D. L., Petrology of the mantle, Mineralog. Soc. America Spec. Paper, 3, 85-93, 1970.

Anderson, D. L., Chemical stratification of the mantle, Jour. Geophys. Res., v. 84, no. B11, p. 6297-6298, 1979.

Anderson, D. L., Isotopic evolution of the mantle; the role of magma mixing, Earth Planetary Sci. Lett., 57, 1-12, 1982a.

Anderson, D. L., The chemical composition and evolution of the mantle, in Advances in Earth and Planet. Sci., v. 12, High-pres- 
sure research in geophysics, edited by S. Akimoto and M. H. Manghnani, 301-318, $1982 \mathrm{~b}$.

Anderson, D. L., Chemical composition of the mantle, Jour. Geophys. Res., v. 88 supplement, p. B41-B52, 1983.

Anderson, D. L., A seismic equation of state II. Shear properties and thermodynamics of the lower mantle, Phys. Earth Planet. Interiors 45, 307-323, $1987 \mathrm{a}$.

Anderson, D. L., Thermally induced phase changes, lateral heterogeneity of the mantle, continental roots and deep slab anomalies, Jour. Geophys. Res. 92, 13,968-13,980, 1987b.

Anderson, D. L., Theory of the Earth, Blackwell Scientific Publications, Boston, 366 pp., 1989a. (http://resolver._Caltech.edu/ CaltechBOOK:1989.001)

Anderson, D. L., Where on Earth is the crust?, Physics Today 38-46, 1989b.

Anderson, D. L., The helium paradoxes, Proc. National Acad. Sci. USA 95, 4822-4827, 1998.

Anderson, D. L., The statistics of helium isotopes along the global spreading ridge system, Geophys. Res. Lett. 27 (16), 2401-2404, 2000.

Anderson, D. L., A statistical test of the two reservoir model for helium isotopes, Earth Planetary Science Letters 193, 77-82, 2001.

Anderson, D. L., The case for the irreversible chemical stratification of the mantle, International Geology Review 44, 97-116, $2002 \mathrm{a}$.

Anderson, D. L. Plate tectonics as a far-from-equilibrium selforganized system, in Plate Boundary Zones, AGU Geodynamics Series, 30, 411-425, 2002b.

Anderson, D. L., and Anderson, O. L., The bulk modulus-volume relationship for oxides, Jour. Geophys. Res. 75(17), 3494-3500, 1970.

Anderson, D. L., and Bass, J. D., Mineralogy and composition of the upper mantle: Geophys. Res. Lett. 11, 637-640, 1984.

Anderson, D. L., Sammis, C. G., and Jordan, T. H., Composition and evolution of the mantle and core, Science 171, no. 3976, p. 1103-1112, 1971.

Anderson, O. L., Equations of state of solids for geophysics and ceramic science, Oxford University Press, New York, 405 pp., 1995.

Armstrong, R. L., Radiogenic isotopes: The case for crustal recycling on a near-steady-state no-continental-growth Earth, Royal Society of London Philosophical Transactions, v. 301, 443-472, 1981.

Armstrong, R. L., The persistent myth of crustal growth, Australian Journal of Earth Sciences 38, 613-630, 1991.

Baig, A. M. and F. A. Dahlen, Traveltime biases in random media and the S-wave discrepancy, Geophysical Journal International 158, 922-938, 2004, doi:10.1111/j.1365-246X.2004.02341.x

Badro, J., G. Fiquet, F. Guyot, J.-P. Rueff, V. V. Struzhkin, G. Vankó, and G. Monaco, Iron partitioning in Earth's mantle: Toward a deep lower-mantle discontinuity, Science, 300, 789, 2003.

Ballentine, C. J., D. C. Lee, and A. N. Halliday, Hafnium isotopic studies of the Cameroon line and new HIMU paradoxes, Chem. Geol. 139, 111-124, 1997.
Ballentine, C. J., Van Keken, P. E., Porcelli, D., Hauri, E. H., Numerical models, geochemistry and the zero-paradox noble-gas mantle. Philos Transact Ser A Math Phys Eng Sci. 360(1800):2611-31, 2002.

Becker, T. W., and L. Boschi, A comparison of tomographic and geodynamic mantle models, Geochem. Geophys. Geosyst., 3, 2001GC000168, 2002.

Becker, T. W., Kellogg, J. B., and O'Connell, R. J., Thermal constraints on the survival of primitive blobs in the lower mantle, Earth and Planetary Science Letters 171, 351, 1999.

Bina, C. R., Mantle discontinuities, Rev. Geophys. Suppl., 783-793, 1991.

Birch, F., Elasticity and constitution of the Earth's Interiors, J. Geophys. Res. 57, 227-286, 1952.

Birch, F., Composition of the earth's mantle, Geophys. J. R. Astron. Soc. 4, 295-311, 1961.

Boschi, L., and A. Dziewonski, High- and low-resolution images of the Earth's mantle, J. Geophys. Res. 104, 25,567-25,594, 1999.

Bullen, K., An Introduction to the Theory of Seismology, Cambridge University Press, Cambridge, 276 pp, 1947.

Bunge, H.-P., Ricard, Y., and J. Matas, Non-adiabaticity in mantle convection, Geophys. Res. Lett., 28, 879-882, 2001.

Chandrasekhar, S., Hydrodynamic and Hydromagnetic Stability, Dover Publishing, New York, 654, 1961.

Christensen, U. R., and A. Tilgner, Power requirement of the geodynamo from ohmic losses in numerical and laboratory dynamos, Nature 429, 169-171, 2004, doi:10.1038/nature02508.

Cizkova, H., and C. Matyska, Layered convection with an interface at a depth of $1000 \mathrm{~km}$ : Stability and generation of slablike downwellings, Phys. Earth Planet. Int. 141, 269-279, 2004.

Clark, S. P., and K. K. Turekian, Thermal constraints on the distribution of long-lived radioactive elements in the Earth, Phil. Trans. R. Soc. Lond. 291, 269-275, 1979.

Coltice, C., and Y. Ricard, Geochemical observations and one-layer mantle convection, Earth Planet. Sci. Lett. 174, 125-137, 1999.

Cordery, M. J., Davies, G. F., and Campbell, I. H., Genesis of flood basalts from eclogite-bearing mantle plumes, J. Geophys. Res. 102, 20,179-20,197, 1997.

da Silva, C, R. S., R. M. Wentzcovitch, A. Patel, G. D. Price, and S. I. Karato, The composition and geotherm of the lower mantle: Constraints from the elasticity of silicate perovskite, Physics of the Earth and Planetary Interiors 118, 103-109, 2000.

Davaille, A., Two-layer thermal convection in miscible viscous fluids, J. Fluid Mech. 379, 223-253, 1999.

Davies, G. F., Effective elastic-moduli under hydrostatic stress.1. Quasi-harmonic theory, Journal of Physics and Chemistry of Solids 35(11), 1513-1520, 1974.

Davies, G. F., Ocean bathymetry and mantle convection 1. Large-scale flow and hotspots, J. Geophys. Res. 93, 10,467-10,480, 1988.

Davies, G. F., Mantle plumes, mantle stirring and hotspot chemistry, Earth Planet. Sci. Lett. 99, 94-109, 1990.

DePaolo, D. J., Crustal growth and mantle evolution: Inferences from models of element transport and $\mathrm{Nd}$ and $\mathrm{Sr}$ isotopes, $\mathrm{Geo}-$ chim. Cosmochim. Acta 44, 1185-96, 1980. 
DePaolo, D., and G. J. Wasserburg, Inferences about magma sources and mantle structure from variations of ${ }^{143} \mathrm{Nd} /{ }^{144} \mathrm{Nd}$, Geophys. Res. Lett. 3, 743-746, 1976.

DePaolo, D. J., and M. Manga, Deep origin of hot spots-the mantle plume model, Science 300(5621), 920-921, 2003.

Deuss, A., and J. H. Woodhouse, A systematic search for mantle discontinuities using SS-precursors, Geophys. Res. Lett. 29, 10.1029/2002GL014768, 2002

Dubuffet, F., Yuen, D. A., and Rainey, E. S. G., Controlling thermal chaos in the mantle by positive feedback from radiative thermal conductivity, Nonlinear Processes in Geophysics 9, 311-323, 2002.

Duffy, T. S., and D. L. Anderson, Seismic velocities in mantle minerals and the mineralogy of the upper mantle, Jour. Geophys. Res. 94, 1895-1912, 1989.

Dziewonski, A. M., The robust aspects of global seismic tomography, in Plates, Plumes \& Paradigms, Foulger, G. R., Natland, J. H., Presnall, D. C, and Anderson, D. L., eds., Boulder, CO, Geological Society of America, 2005.

Dziewonski, A. M., Global seismic tomography: What we really can say and what we make up, 2004. (www.mantleplumes.org/ Penrose/PenPDFAbstracts/DziewonskiAdam_abs.pdf)

Dziewonski, A. M., and D. L. Anderson, Preliminary Reference Earth Model, Phys. Earth Planet. Interiors 25, 297-356, 1981.

Elder, J., The Bowels of the Earth, Oxford Univ. Press, Oxford, 1976.

Elsasser, W. M., P. Olson, and B. D. Marsh, The depth of mantle convection, Jour. Geophys. Research 84, 147-154, 1979.

Fee, D., and K. Dueker, Mantle transition zone topography and structure beneath the Yellowstone hotspot, Geophys. Res. Lett. 31, L18603, doi:10.1029/2004.

Forte, A. M., and J. X. Mitrovica, Deep-mantle high-viscosity flow and thermochemical structure inferred from seismic and geodynamic data, Nature 402, 1881-1884, 2001.

Fukao, Y., Widiyantoro, S., and Obayashi, M., Stagnant slabs in the upper and lower mantle transition region, Rev. Geophy. 28, 291-323, 2001.

Gaffney, E. S., and D. L. Anderson, The effect of low-spin Fe on the composition of the lower mantle, J. Geophys. Res. 78, 7005-7014, 1973.

Garnero, E., and D. Helmberger, A very slow basal layer underlying large-scale low-velocity anomalies in the lower mantle beneath the Pacific, Phys. Earth Planet. Interiors 91, 161-176, 1995.

Gasparik, T., A model for the layered upper mantle, Phys. Earth Planet. Interiors 100, 197-212, 1997.

Gerlack, D. C., Eruption rates and isotopic systematics of ocean islands: Further evidence for small-scale heterogeneity in the upper mantle, Tectonophysics 172, 273-289, 1990.

Goes, S., R. Govers, and P. Vacher, Shallow mantle temperatures under Europe from $\mathrm{P}$ and $\mathrm{S}$ wave tomography, J.Geophys. Res. 105, 11,153-11,169, 2000.

Gu, Y., Dziewonski, A. M., Weijia, S., and Ekstrom, G., Models of the mantle shear velocity and discontinuities in the pattern of laterai heterogeneities, J. Geophys. Res. 106, 11,169-11,199, 2001.

Hager, B. W., R. W. Clayton, M. A. Richards, R.P . Comer, and A. Dziewonski, Lower mantle heterogeneity, dynamic topography and the geoid, Nature 313 (6003), 541-545, 1985.
Hager, B. H., and R. W. Clayton, Constraints on the structure of mantle convection using seismic observations, flow models, and the geoid, in Mantle Convection, R. W. Peltier. Gordon and Breach. New York, pp. 657-763, 1989.

Hamilton, W. B., The closed upper-mantle circulation of plate tectonics, in Plate Boundary Zone, S. Stein, ed., AGU Monograph, 2002.

Helffrich, G. R., and Wood, B. J., The Earth's mantle, Nature 412, 501-507, 2001.

Hirth, G., and D. L.Kohlstedt, Water in the oceanic upper mantle: Implications for rheology, melt extraction and evolution of the lithosphere, Earth Planet. Sci. Lett. 144, 93-108, 1996.

Hofmann, A. W., Mantle geochemistry: The message from oceanic volcanism, Nature 385, 219-229, 1997.

Hofmeister, A. M., Mantle values of thermal conductivity and a geotherm from phonon lifetimes, Science 283, 1699-1706, 1999.

Howard, L. N., Convection at high Rayleigh number, in Proceedings of the 11th Congress of Applied Mechanics, Munich (Germany), H. Gortler, ed., pp. 1109-1115, Springer-Verlag, Berlin, 1966.

Ishii, M., and J. Tromp, Constraining large-scale mantle heterogeneity using mantle and inner-core sensitive modes, Physics Earth Planet. Interiors 146, 113-124, 2004.

Ita, J. J., and S. D. King, The influence of thermodynamic formulation on simulations of subduction zone geometry and history, Geophys. Res. Lett. 125, 1463-1466, 1998.

Jacobsen, S. B., and G. J. Wasserburg, The mean age of mantle and crustal reservoirs, J. Geophys. Res. 84, 7411-7427, 1979.

Javoy, M., The integral enstatite chondrite model of the Earth. Geophys. Res. Lett. 22, 2219-2222, 1995.

Jordan, T. H., Lithospheric slab penetration into the lower mantle beneath the sea of Okhotsk, J. Geophys. Res. 43, 473-496, 1977.

Julian, B. R., Seismology: The hunt for plumes, 2004. (http://www. mantleplumes.org/Seismology.html)

Kawakatsu, H., and F. Niu, Seismic evidence for a 920-km discontinuity in the mantle, Nature 371, 301-305, 1994.

Kellogg, L. H., and G. J. Wasserburg, The role of plumes in mantle helium fluxes, Earth Planet. Sci. Lett. 99, 276-289, 1990.

Kellogg, L. H., B. H. Hager, and R. D. van der Hilst, Compositional stratification in the deep mantle, Science 410, 1049-1056, 1999.

Kiefer, B., L. Stixrude, and R. M. Wentzcovitch, Elasticity of $(\mathrm{Mg}, \mathrm{Fe}) \mathrm{SiO}_{3}$-perovskite at high pressures, Geophys. Res. Lett., 29, art. no. 014683, 2002.

Lay, T., The deep mantle thermo-chemical boundary layer: the putative mantle plume source, 2005. (http://www.mantleplumes. org/TopPages/TheP3Book.html)

Lay, T., Q. Williams, and E.Garnero, The core--mantle boundary layer and deep Earth dynamics: Nature 392, 461-468, 1998.

Lee, C.-T., Compositional variation of density and seismic velocities in natural peridotites at STP conditions: Implications for seismic imaging of geochemical heterogeneities in the upper mantle, J. Geophys. Res. 108, 2003, doi:10.1029/2003JB002413.

Lee, K. K. M., B. O'Neill, W. R. Panero, S.-H. Shim, L. R. Benedetti, and R. Jeanloz, Equations of state of the high-pressure phases of a natural peridotite and implications for the Earth's 
lower mantle, Earth Planet. Sci. Lett. 223(3-4), 381-393, 2004.

Lenardic, A., and W. M. Kaula, Tectonic plates, D" thermal structure, and the nature of mantle plumes, J. Geophys. Res., 99, 15,697-15,708, 1994

Levander, A., and F. Niu, Receiver-function imaging of the crustal and mantle structure beneath South Africa: A comparison of stacking and migration, EOS Trans. 84, 46, 2003.

Li, J., V. Struzhkin, H.-K. Mao, J. Shu, R. J. Hemley, Y. Fei, B. Mysen, P. Dera, V. Prakapenka, and G.Shen, Electronic spin state of iron in lower mantle perovskite, Proc. Natl. Acad. Sci. USA 101, 14,027-14,030, 2004.

Loper, D. E., and F. D. Stacey, The dynamical and thermal structure of deep mantle plumes, Phys. Earth Planet.. Interiors 33, 304-317, 1983.

Lubimova, H., Thermal history of the Earth with consideration of the variable thermal conductivity of the mantle, Geophys. J Roy. Astron. Soc. 1, 115-134, 1958.

Mattern, E., J. Matas, Y. Ricard, and J. Bass, Lower mantle composition and temperature from mineral physics and thermodynamic modeling, Geophys. J. Int. 160, 973-990, 2005.

McKenzie, D. P., and F. Richter, Parameterized thermal convection in a layered region and the thermal history of the Earth, J. Geophys. Res. 86, 11,667-11,680, 1981.

Meibom, A., and Anderson, D. L., The statistical upper mantle assemblage, Earth Planet Sci. Lett. 217, 123-139, 2003. (www. mantleplumes.org/Preprints.html)

Mitrovica, J. X., and Forte, A. M., Radial profile of mantle viscosity: Results from the joint inversion of convection and postglacial rebound observable, J. Geophys. Res. 102, 2751-2769, 1997.

Murakami, M., Hirose, K., Kawamura, K., Sata, N., and Ohishi, Y., Post-perovskite phase transition in $\mathrm{MgSiO}_{3}$, Science 304, 855-858, 2004.

Nataf, H.-C., Mantle convection, plates, and hotspots, Tectonophysics 187, 361-377, 1991.

Olsen, P. L., D. A. Yuen, and D. S. Balsiger, Mixing of passive heterogeneities by mantle convection, J. Geophys. Res. 89, 425-36, 1984.

O'Nions, R. K., Evensen, N. M., and Hamilton, P. J., Differentiation and evolution of the mantle, Philos. Trans. Roy. Soc. Lond. A 297, 479-93, 1980.

O'Nions, R. K., and R. Oxburgh, Heat and helium in the Earth. Nature 306, 429-431, 1983.

Perry, H. K. C., A. M. Forte, and D. W. S. Eaton, Upper mantle thermochemical structure below North America from seismic geodynamic flow model, Geophys. J. Int. 154, 279-299, 2003.

Phillips, B. R,. and H-P. Bunge, Heterogeneity and time dependence in 3D spherical mantle convection models with continental drift, Earth Planet. Sci. Lett. 233(1-2), 121-135, 2005.

Presnall, D. C., and G. H. Gudfinnsson, Carbonatitic melts in the oceanic low-velocity zone and deep upper mantle, in Plates, Plumes \& Paradigms, G. R. Foulger, J. H. Natland, D. C. Presnall, and D. L. Anderson, eds., Geological Society of America, 2005 (in press).
Ringwood, A. E., Composition and phases of the mantle, in Advances in Earth Sciences, P. M. Hurley, ed., MIT Press, Cambridge, Mass., 502 pp., 1966.

Ringwood, A. E., Compositions and Petrology of the Earth's Mantle, McGraw-Hill, New York, 618 pp., 1975.

Ringwood, A. E., Origin of the Earth and Moon, Springer-Verlag, New York, 1979.

Ritsema, J., Global seismic maps, Web supplement, 2005. (http:// www.mantleplumes.org/TopPages/TheP3Book.html)

Ritsema, J., van Heijst, H. J., and Woodhouse, J. H., Complex shear wave velocity structure imaged beneath Africa and Iceland, Science 286, 1925-1928, 1999.

Rost, S., and E. J. Garnero, Array seismology advances research into Earth's Interior, Eos Trans. 85, 301, 305-306, 2004.

Rudnick, R. L., and D. M. Fountain, Nature and composition of the continental crust: A lower crustal perspective, Rev. Geophysics 33, 267-309, 1995.

Sammis, C. G., D. L. Anderson, and T. H. Jordan, Application of isotropic finite strain theory to ultra-sonic and seismological data, Jour, Geophys. Res. 75(23), 478-480, 1970.

Sarda, P., and D. W. Graham, Mid-ocean ridge popping rocks: Implications for degassing at ridge crests, Earth Planet. Sci. Lett. 97, 268-289, 1990.

Schubert, G., Turcotte, D. L., and Olsen, P., Mantle Convection in the Earth and Planets, Cambridge University Press, Cambridge, 2001.

Scrivner, C., and Anderson, D. L., The effect of post Pangea subduction on global mantle tomography and convection, Geophys. Res. Lett. 19, 1053-1056, 1992.

Shapiro, N. M., and M. H. Ritzwoller, Thermodynamic constraints on seismic inversions, Geophys. J. Int. 157, 1175-1188, doi:10.1111/j.1365-246X.2004.02254.x, 2004.

Shearer, P. M., and Earle, P. S., Modeling the global short-period wavefield with a Monte Carlo seismic phonon method, submitted, 2004.

Silver, P. G., R. W. Carlson, and P. Olson, Deep slabs, geochemical heterogeneity and the large-scale structure of mantle convection: Investigation of an enduring paradox, Ann. Rev. Earth Planet. Sci. 16, 477-541, 1988.

Song, T. R. A., D. V. Helmberger, and S. Grand, Low velocity zone atop the 410 seismic discontinuity in the northwestern US, Nature 427, 530-533, 2004.

Spakman, W., and G. Nolet, Imaging algorithms, accuracy and resolution in delay time tomography, in Mathematical Geophysics, Vlaar et al. (eds.), Reidel, pp. 155-188, 1988.

Spakman, W., S. Stein, R. D. Van der Hilst, and R. Wortel, Resolution experiments for NW Pacific subduction zone tomography, Geophys. Res. Lett. 16, 1097-1100, 1989.

Stacey, F. D., Properties of a harmonic lattice, Phys. Earth Planet. Interiors 78, 19-22, 1993.

Stacey, F. D., and Loper, D. E., The thermal boundary-layer interpretation of $\mathrm{D}^{\prime \prime}$ and its role as a plume source, Phys. Earth Planet. Interiors 33, 45-55, 1983.

Stacey, F. D., and D. G. Isaak, Extrapolation of lower mantle properties to zero pressure: Constraints on composition and temperature, Amer. Mineralogist 85, 345-353, 2000. 
Stein, C., J. Schnalzl, and U.Hansen, The effect of rheological parameters on plate behavior in a self-consistent model of mantle convection, Phys. Earth Planet. Interiors 142, 225-255, 2004.

Tackley, P., Mantle convection and plate tectonics: Toward an integrated physical and chemical theory, Science 288, 2002-2007, 2000.

Tackley, P., Three-dimensional simulations of mantle convection with a thermo-chemical basal boundary layer: $\mathrm{D}^{\prime \prime}$, in Gurnis, M., Wysession, M. E., Knittle, K., and Buffett, B., eds., The Core-Mantle Boundary Region, American Geophysical Union, Washington, D.C., pp. 231-253, 1998.

Tanimoto, T., Predominance of large-scale heterogeneity and the shift of velocity anomalies between the upper and lower mantle, J. Phys. Earth 38, 493, 1990.

Thybo, H., and E. Perchuc, The seismic 8-degree discontinuity and partial melting in the continental mantle, Science 275 , 1626-1629, 1997.

Trampert, J., P. Vacher, and N. Vlaar, Sensitivities of seismic velocities to temperature, pressure and composition in the lower mantle, Phys. Earth Planet. Interiors 124, 255-267, 2001.

Trampert, J., F. Deschamps, J. Resovsky and D. Yuen, Probabalistic tomography maps chemical heterogeneities throughout the lower mantle, Science.306, 853-856, 2004.

van der Hilst, R. D., Widiyantoro, S., and Engdahl, E. R., Evidence of deep mantle circulation from global tomography, Nature 386 , 578-584, 1997.

van der Hilst, R. D., Changing views on Earth's deep mantle, Science 306, 817-818, 2004. van Keken, P., E. H. Hauri, and C. J. Ballentine, Mantle mixing: The generation, preservation, and destruction of chemical heterogeneity, Annual Rev. Earth Planet. Sci. 30, 493-525, 2002.

Vasco, D. W., L. R. Johnson, R. J. Pulliam, and P. S. Earle, Robust inversion of IASP91 travel time residuals for mantle $\mathrm{P}$ and $\mathrm{S}$ velơcity structure, earthquake mislocations, and station corrections, J. Geophys. Res. 99, 13,727-13,755, 1994.

Wen, L., and D. L. Anderson, The fate of slabs inferred from seismic tomography and 130 million years of subduction, Earth Planet Sci. Lett. 133, 185-198, 1995.

Wen, L., and D. L. Anderson, Layered mantle convection: A model for geoid and topography, Earth Planet. Sci. Lett. 146, 367-377, 1997.

Whitcomb, J. H., and D. L. Anderson, Reflection of P'P' seismic waves from discontinuities in the mantle, Jour. Geophys. Res. 75(29), 5713-5728, 1970.

Zhao, Y., and D. L. Anderson, Mineral physics constraints on the chemical composition of the Earth's lower mantle, Phys. Earth Planet. Interiors 85, 273-292, 1994.

Zindler, A., and S. R. Hart, Chemical geodynamics, Ann. Rev. Earth Planet Sci. 14, 493-571, 1986.

Zindler, A., H. Staudigel, and R. Batiza, Isotope and trace element geochemistry of young Pacific seamounts: Implications for the scale of mantle heterogeneity. Earth Planet. Sci. Lett. 70, 175-195, 1984.

Don L. Anderson, Seismological Laboratory, California Institute of Technology, MC 252-21, Pasadena, CA 91125 (dla@gps. caltech.edu) 